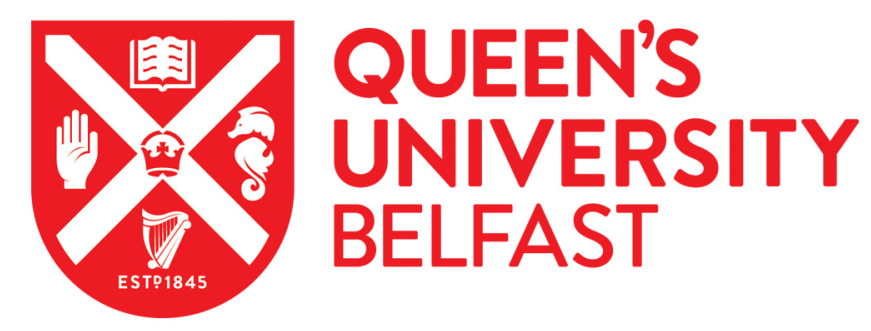

\title{
Filament Extrusion of Bioresorbable PDLGA for Additive Manufacturing utilising Diatom Biosilica to inhibit process-induced thermal degradation
}

Han, R., Buchanan, F., Julius, M., \& Walsh, P. (2021). Filament Extrusion of Bioresorbable PDLGA for Additive Manufacturing utilising Diatom Biosilica to inhibit process-induced thermal degradation. Journal of the Mechanical Behavior of Biomedical Materials, [104265]. https://doi.org/10.1016/j.jmbbm.2020.104265

Published in:

Journal of the Mechanical Behavior of Biomedical Materials

Document Version:

Peer reviewed version

Queen's University Belfast - Research Portal:

Link to publication record in Queen's University Belfast Research Portal

\author{
Publisher rights \\ (C) 2021 Elsevier Ltd. \\ This manuscript version is made available under the CC-BY-NC-ND 4.0 license http://creativecommons.org/licenses/by-nc-nd/4.0/,which \\ permits distribution and reproduction for non-commercial purposes, provided the author and source are cited.
}

\section{General rights}

Copyright for the publications made accessible via the Queen's University Belfast Research Portal is retained by the author(s) and / or other copyright owners and it is a condition of accessing these publications that users recognise and abide by the legal requirements associated with these rights.

Take down policy

The Research Portal is Queen's institutional repository that provides access to Queen's research output. Every effort has been made to ensure that content in the Research Portal does not infringe any person's rights, or applicable UK laws. If you discover content in the

Research Portal that you believe breaches copyright or violates any law, please contact openaccess@qub.ac.uk. 


\section{Journal Pre-proof}

Filament extrusion of bioresorbable PDLGA for additive manufacturing utilising diatom biosilica to inhibit process-induced thermal degradation.

R. Han, F. Buchanan, M. Julius, P.J. Walsh

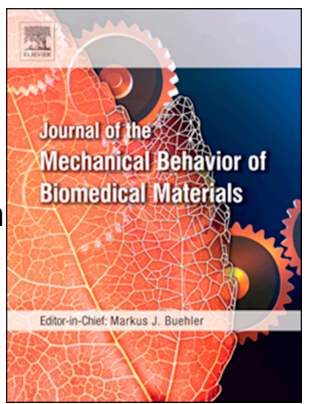

PII: S1751-6161(20)30802-X

DOI: $\quad$ https://doi.org/10.1016/j.jmbbm.2020.104265

Reference: JMBBM 104265

To appear in: Journal of the Mechanical Behavior of Biomedical Materials

Received Date: 28 May 2020

Revised Date: 23 November 2020

Accepted Date: 9 December 2020

Please cite this article as: Han, R., Buchanan, F., Julius, M., Walsh, P.J., Filament extrusion of bioresorbable PDLGA for additive manufacturing utilising diatom biosilica to inhibit process-induced thermal degradation., Journal of the Mechanical Behavior of Biomedical Materials (2021), doi: https:// doi.org/10.1016/j.jmbbm.2020.104265.

This is a PDF file of an article that has undergone enhancements after acceptance, such as the addition of a cover page and metadata, and formatting for readability, but it is not yet the definitive version of record. This version will undergo additional copyediting, typesetting and review before it is published in its final form, but we are providing this version to give early visibility of the article. Please note that, during the production process, errors may be discovered which could affect the content, and all legal disclaimers that apply to the journal pertain.

(C) 2020 Published by Elsevier Ltd. 


\section{Author Statement}

R. Han (RH), F. Buchanan (FB), M. Julius (MJ), PJ Walsh (PJW)

RH, FB, PJW - Conceptualization; RH - Data curation; RH, PJW - Formal analysis; MJ Statistical analysis, RH (Self-funded PhD with 1-year Beaufort Marine Biodiscovery Programme - FB) Funding acquisition; RH, FB, PJW - Methodology; RH \& PJW Writing original draft; All authors - Writing - review \& editing. 
$1 \quad$ Revision 3: $23^{\mathrm{RD}}$ Nov 2020

2 Title: Filament Extrusion of Bioresorbable PDLGA for Additive Manufacturing utilising

3 Diatom Biosilica to inhibit process-induced thermal degradation.

4

\author{
Authors: R. $\operatorname{Han}^{1}$, F. Buchanan ${ }^{2}$, M. Julius ${ }^{3}$, PJ Walsh ${ }^{1}$ \\ ${ }^{1}$ School of Chemistry \& Chemical Engineering, Queen's University Belfast, ${ }^{2}$ School of Mechanical \& Aerospace \\ Engineering, Queen's University Belfast, UK, 'Biological Sciences, St. Cloud State University, St. Cloud, MN, \\ USA.
}

\title{
Abstract:
}

Bone scaffolds are often fabricated by initially producing custom-made filaments by twinscrew extruder and subsequently fabricating into 3D scaffolds using fused deposition modelling. This study aims to directly compare the effect of two alternative silica-rich filler materials on the thermo-mechanical properties of such scaffolds after extrusion and printing. Poly (DL-lactide-co-glycolide) (PDLGA) was blended with either 45S5 Bioglass (5 wt \%) or Biosilica (1 and $5 \mathrm{wt} \%$ ) isolated from Cyclotella meneghiniana a freshwater diatom were tested. Diatom-PDLGA was found to have similar mechanical strength and ductility to pure-PDLGA, whereas Bioglass-PDLGA was found induce a more brittle behaviour. BioglassPDLGA was also found to have the lowest toughness in terms of energy absorption to failure. The TGA results suggested that significant thermal degradation in both the Bioglass filaments and scaffolds had occurred as a result of processing. However, diatom biosilica was found to inhibit thermal degradation of the PDLGA. Furthermore, evidence suggested the agglomeration of Bioglass particles occurred during processing the Bioglass-PDLGA filaments. Overall, diatom biosilica was found to be a promising candidate as a bone filler additive in 3D printed PDLGA scaffolds, whereas Bioglass caused some potentially detrimental effects on performance. 
Key Words: Bioresorbable Scaffolds, 3D FDM Scaffolds, Bioglass, Diatoms, Additive

Manufacture

\section{Introduction:}

31 Bioglass (based on the system $\mathrm{SiO}_{2}-\mathrm{CaO}-\mathrm{Na}_{2} \mathrm{O}$ and $\mathrm{P}_{3} \mathrm{O}_{5}$ ) has been reported to have superior performance in bone regeneration in comparison to other ceramics, however, has had issues in its clinical translation, mainly owning to difficulties with its fabrication into composite/hybrid materials for load bearing applications ${ }^{1}$. Recently several studies, however, have reported more promising results with 3D printing of Bioglass-polymer composites $^{2-4}$ suggesting that this fabrication technique may be more suitable for Bioglass.

The downside of this is that there would seem to be an interaction between Bioglass and the polymer during melt-processing which results in the thermal degradation of the polymer and a detrimental lowering of mechanical properties, such as strength ${ }^{5}$. Interestingly natural biosilica isolated from diatoms has also started to show promise in bone repair ${ }^{6-9}$, which may offer an alternative silica filler option for 3D printed scaffolds. Diatom frustules (the cell walls of diatoms) are unique silica particles that host surface topographies that cannot be replicated synthetically. They range in particle size from $2 \mu \mathrm{m}$ to $2 \mathrm{~mm}$ depending on the species, each with unique morphologies that vary in surface area dependent on its topographical features ${ }^{10}$. To date there have been no reports published on the influence of biosilica from diatoms on the mechanical properties of melt-processed biosilica polymer composites.

To build 3D composite scaffolds with 3D printing, bioresorbable polymers, such as

50 poly(lactic acid) (PLA), poly(ethylene glycol) (PEG), and poly(lactic-co-glycolic acid) (PLGA)

51 have been reinforced with ceramics including hydroxyapatite (HA) and tricalcium 
52 phosphates ${ }^{11,12}$. Other ceramic materials embedded in polymers have also been

53 investigated for bone repair to a much lesser extent, these include strontium substituted

$54 \mathrm{HA}$, and silica ${ }^{13-15}$. Poly (DL-lactide-co-glycolide) (PDLGA) also shows good potential in 3D

55 printing ${ }^{16,17}$ in terms of processing, forming and repeatability of scaffold architectures,

56 however, it has been less studied ${ }^{18,19}$ in terms of thermal processing degradation when

57 compared to other non-medical grade polymers ${ }^{19}$.

58 The success of 3D printing relies heavily on the quality of filaments used in the print process.

59 For composite filaments, good homogeneity and dispersion of incorporated filler particles is

60 required to achieve good printability ${ }^{20}$. Filaments can be pre-fabricated using a range of

61 techniques including hot melt or single/twin-screw extrusion ${ }^{20-23}$, or some 3D printers melt

62 the polymers directly in a one-step process ${ }^{24}$. Twin-screw extrusion has been reported to

63 produce a more homogeneous distribution of ceramics particles within the polymer matrix

64 in composite filaments than comparator techniques ${ }^{25}$ However, caution should be taken

65 when selecting a suitable filament/scaffold fabrication method as they can cause thermally

66 induced degradation, which could affect their clinical performance. Little et al., ${ }^{18}$ reported

67 less thermal degradation in PDLGA filaments produced by twin-screw extrusion, compared

68 to a study by Yen et al., ${ }^{17}$ that used a single hot melt extrusion FDM process to produce

69 PDLGA filaments. Little et al. demonstrated that the thermal degradation was a function of

70 both exposure time and temperature during melt-processing. Important physical-chemical

71 material properties of filaments for 3D printing that should be considered include

72 rheological, molecular, microstructural and mechanical ${ }^{22}$.

74 In addition to process-induced thermal degradation, ceramics added to bioresorbable polymers, have been reported to induce a reduction in thermo-mechanical properties of the 
material. A study by Simpson et al. reported significant polymer degradation in PLGA after the incorporation of Bioglass 45S5, when compared to other ceramic fillers ${ }^{5}$. The study attributed the decrease in thermo-mechanical properties to be a result of a reduction in molecular weight due to thermally induced degradation. Under these processing conditions, the performance of bioglass as a filler to PLDGA has shown less promise to that of biosilica.

The novelty of the study lies with the application of diatom biosilica as a potential filler material for tissue engineered scaffolds. It investigates the use of twin-screw extrusion to fabricate tailored PDLGA filaments containing either bioglass or diatom biosilica filler to establish if biosilica is suitable for 3D printing of bone tissue scaffolds, compared to bioglass, which has previously been reported to not be suitable ${ }^{5}$. The study investigates the effect of adding the two different filler types on the thermo-mechanical properties of PDLGA after extrusion and printing. In this study, Bioglass ${ }^{\circledR} 45 \mathrm{~S} 5$ (trade name PerioGlas ${ }^{\oplus}$ ) was compounded with PDLGA and compared to natural silica filler similarly compounded into PDLGA using twin-screw extrusion. This allowed direct comparison to be made with respect to the composite properties due to the filler additions. The natural silica was isolated from a fresh water diatom (Cyclotella meneghiniana) that was then purified to remove all organic matter. The species selected, $C$. meneghiniana is a centric diatom with a particle size in the range of 10 to $20 \mu \mathrm{m}^{26}$. Biosilica isolated from diatoms was selected for this study owing to its unique morphology that creates a high surface $a r e a^{10}$ and their potential osteogenic and angiogenic attributes ${ }^{27-29}$. It was hypothesised that their unique physiochemical properties with nano-sized topographical features ${ }^{6}$ could indroduce silica to the polymer matrix without the detrimental process-induced degradation that has been report for bioglass. 


\section{Materials and Methods}

\subsection{Materials}

Medical grade PDLGA (85:15) ratio DL-LA/GA polymer granules (Boehringer Ingelheim

107 Resomer RG 859 SR) was kept in a sealed bag and stored in the fridge at $-4{ }^{\circ} \mathrm{C}$ to prevent

108 the degradation of polymer prior to use. This was then brought to room temperature and defrosted overnight before compounding with the ceramic fillers. After defrosting, the

110 sealed bag was opened, and PDLGA polymer was weighed and vacuum dried at $40^{\circ} \mathrm{C}$ at 10

111 mbar pressure for 2 days. Bioglass $45 S 5$ (Sylc ${ }^{T M}$, Research Ltd, London, UK) from Denfotex

112 (EJR, D095325/K062502, Reg. No. 872.6030) of mean particle size of 5 to $80 \mu \mathrm{m}$ was used in

113 this study. It was vacuum dried as per PDLGA prior to use. Fresh water diatoms were

114 collected from the Mississippi River, USA and cultured at St. Cloud University using a previously described culture method by Walsh et al., ${ }^{6}$. The species of diatoms selected are

116 known to have frustules with a mean particle of $20 \mu \mathrm{m}$ depending on the growth stage ${ }^{30}$

117 After harvesting, the diatoms frustules were digested in by nitric acid $\left(\mathrm{HNO}_{3}\right)$ to partially

118 remove the organic fraction, then freeze dried and sealed in a vacuum-packed bag for 119 transport to the UK.

120

\subsection{Methods}

\subsubsection{Diatom Purification}

The resultant diatom frustules on arrival from St. Cloud were washed with deionised (DI) water to neutralise the residual acid. The diatom powders were placed in a Buchner funnel 
and washed about 10 times with $1000 \mathrm{ml}$ of DI water per wash. After that, the resultant

127 washed diatoms were dried in an oven at $60{ }^{\circ} \mathrm{C}$ overnight to remove the moisture. The

128 washed diatoms were then heated treated in an air atmosphere in an Elite chamber furnace

129 (BMF 11/7) to remove the residual organic matter that was not removed during the nitric

130 acid wash. A ramp rate of $10^{\circ} \mathrm{C} / \mathrm{min}$ was used with a 1-hour dwell at $550{ }^{\circ} \mathrm{C}$. The samples

131 were then cooled overnight. The purified biosilica frustules were then vacuum dried as

132 previously described. At each stage of the treatments the samples were characterised. The

133 sample references for each treatment are shown in Table 1. Thermogravimetric Analysis

134 (TGA) and CHNS analysis was used to verify that the organics were removed, BET gas porosimetry was used to determine change in specific surface area after treatments and

136 Scanning Electron Microscope (SEM) was used to verify that the frustules remained intact 137 after purification.

\begin{tabular}{|c|c|l|}
\hline Reference ID & Treatment No. & Treatments \\
\hline AT & 1 & Acid wash (St. Cloud) \\
\hline WT & 2 & Wash treatment \\
\hline HT & 3 & Heat treatment \\
\hline
\end{tabular}

Table 1: Purification treatment references.

\subsubsection{Blend preparation}

The dried PDLGA polymer and ceramic filler powders (biosilica/Bioglass 45S5) were mixed homogeneously by hand in a dry blend. Blends were prepared of 1 wt \% Diatom-PDLGA, 5 wt \% Diatom-PDLGA and 5 wt \% Bioglass-PDLGA. The filler was added as a dry weight-toweight ratio to PDLGA. After blending the powdered blends were re-dried in a vacuum oven under the same conditions for 24 hours before extrusion.

\subsubsection{Filament Fabrication}


149 Filaments were produced by Haake twin-screw extruder (Thermo Fisher Scientific,

150 Germany). The extrusion process used is shown in Fig. 1a. The chamber was filled with dry

151 nitrogen to minimise hydrolysis of the PDLGA. The feed was then melted by screw barrel

152 heater with controlled temperature in the range of $165^{\circ} \mathrm{C}$ to $175^{\circ} \mathrm{C}$. A chilled air ring and

153 two normal air rings formed the cooling process to lower the temperature (to

154 approximately $60^{\circ} \mathrm{C}$ ) and extend the soft filament length while reducing its diameter to 1.75

$155 \mathrm{~mm}( \pm 0.05)$, which was an acceptable filament size for 3D Printing. The draw-off belts were

156 used to control the pulling speed, which in turn adjusted the diameter of filament. Four

157 types of filaments were fabricated: Pure-PDLGA filament (Control), 1 wt \% Diatom-PDLGA

158 filament, 5 wt \% Diatom-PDLGA filament and 5 wt \% Bioglass-PDLGA filament.

159

160

161

162

\subsubsection{Scaffold Fabrication using Fused Deposition Modelling (FDM) 3D Printing}

The filaments were fabricated into a 3D scaffold using a RepRap Mendel (RepRapPro, UK) 3D printer. The method used to print the scaffolds was similar to that described by Little et al. ${ }^{18}$. Briefly, the architecture of the scaffold was created using SolidWorks 2010, then converted from STL to G-Code using opensource Slic3r 1.2.9. A standard architecture was selected that most widely represents bone scaffolds to validate the concept. The 3D printer head controlled by Printrun (otherwise known as Printerface) software using G-Code. The printing parameters used are detailed in Table 2. To determine the optimum print temperature for each filament composition a trial-and-error approach was taken. The print temperature of pure PDLGA has been reported in the literature in the range of 170 to 200 ${ }^{\circ} \mathrm{C}^{18,31,32}$, subject to type of PDLGA and printer used. Starting with the Pure-PDLGA filament, scaffolds were printed at different temperatures starting at $180{ }^{\circ} \mathrm{C}$ as per Little et al., study ${ }^{18}$, the print temperature was increased in increments of $5^{\circ} \mathrm{C}$ until an optimum print 
173 temperature was achieved. The scaffolds were assessed under a light microscopy in terms

174 of pore structure and shape, and checked for signs of polymer degradation which is visible

175 by colour change in the polymer. This process was repeated for all the filament conditions,

176 however, in the case of $5 \mathrm{wt} \%$ Bioglass-PDLGA filament, lower temperature increments

177 from $180{ }^{\circ} \mathrm{C}$ were trialled as this filament was too soft and dripped as opposed to flowed

178 out of the nozzle at $180{ }^{\circ} \mathrm{C}$. The printer setup is shown in Fig. 1b. The scaffolds were

179 produced using a $90^{\circ} / 90^{\circ}$ laydown pattern. The layer cycle was repeated 12 times to create

180 the scaffold. For each scaffold approximately $150 \mathrm{~mm}$ of filament was used.

181

182

183

184

185

186

187

188

189

190

191

192

193

194

\begin{tabular}{|c|c|lc|}
\hline \multicolumn{1}{|c|}{ Parameters } & Temperature $\left({ }^{\circ} \mathbf{C}\right)$ & \multicolumn{1}{c|}{ Parameters } & Values \\
\hline Platform Temperature & 60 & Fan Speed & $100 \mathrm{rpm}$ \\
\hline Print Temperature: & & Print Speed & $22 \mathrm{~mm} / \mathrm{s}$ \\
\hline Pure-PDLGA & 190 & Travel Speed & $130 \mathrm{~mm} / \mathrm{s}$ \\
\hline PDLGA-Diatoms (1\%) & 220 & Layer height & $0.25 \mathrm{~mm}$ \\
\hline PDLGA-Diatoms (5\%) & 225 & Nozzle diameter & $0.4 \mathrm{~mm}$ \\
\hline PDLGA-Bioglass (5\%) & 165 & Filament diameter & $\approx 1.75 \mathrm{~mm}$ \\
\hline
\end{tabular}

Table 2: FDM Parameters
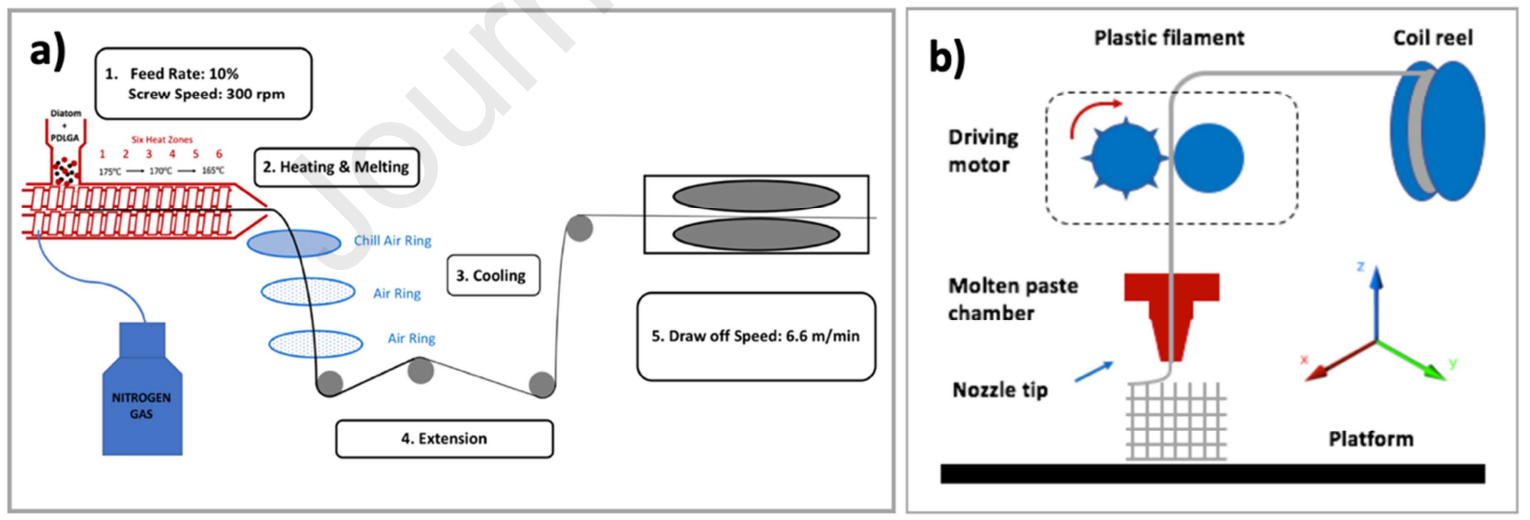

Figure 1: Fabrication processes of (a) filament using twin-screw extrusion and (b) 3D printing of scaffolds.

\subsection{Characterisation}

\subsubsection{Thermogravimetric Analysis (TGA)}

All TGA analysis was performed on a Mettler Toledo (DSC/TGA) 1 Star instrument. Samples were placed in an aluminium crucible and heated under a nitrogen environment. For all 
studies a ramp rate of $10{ }^{\circ} \mathrm{C} / \mathrm{min}$ was used. For the diatom purification study, $5 \mathrm{mg}$ of dried

196 diatom frustules were added to the crucibles for each run. The samples were tested over a

197 temperature range from $25^{\circ} \mathrm{C}$ to $800{ }^{\circ} \mathrm{C}$. For the filaments and 3D printed scaffolds, TGA

198 was used to verify the mass percentage additive and to check the onset temperature to

199 determine if any thermal degradation had taken place. In TGA, the onset temperature is defined as the temperature at which mass loss starts, and is also denoted as the upper limit of thermal stability for polymer ${ }^{33}$. For each filament, samples were taken every $30 \mathrm{~cm} . \mathrm{A}$ total of 5 samples was taken along the filament length. The analysis was replicated on each sample in triplicate. For the scaffolds, samples were taken at random from different samples within the same filament type. The percentage additive was calculated as follows:

\subsubsection{Elemental Analysis}

Elemental analysis was performed on a Perkin Elmer PE2400 CHNS/O Elemental Analyser.

The analyses were run by the QUB Analytical Services and Environmental Projects Division (ASEP) facility. For analysis, the diatom samples for all treatments were dried in an oven at $60{ }^{\circ} \mathrm{C}$ overnight. Prior to analysis, the instrument is purged with helium gas, then calibrated

216 using a series of empty blank vials followed by an Acetanilide ( $C=71.06 ; H=6.71 ; N=10.31$;

$217 \mathrm{O}=11.82$ ) and Cystine $(\mathrm{C}=29.95 ; \mathrm{H}=5.09 ; \mathrm{N}=11.59 ; \mathrm{O}=26.67 ; \mathrm{S}=26.67)$ standards. The diatom sample ( 1 to $2 \mathrm{mg}$ ) was combusted in a sealed tin crucible at $975{ }^{\circ} \mathrm{C}$, then the gas flows into a reduction furnace at $640{ }^{\circ} \mathrm{C}$ prior to collection. In the analysis, $\mathrm{CO}_{2}, \mathrm{H}_{2} \mathrm{O}, \mathrm{N}_{2}$ gases are collected in the mixing chamber, separated by frontal chromatography and measured by

221 thermal conductivity (TC). 


\subsection{3 $\quad \mathrm{N}_{2}$ absorption-desorption analysis}

Brunauer-Emmett-Teller (BET) surface area analysis was performed on a Micromeritics

Tristar 3020 gas adsorption analyser. Prior to analysis the samples were dried in an oven at $60{ }^{\circ} \mathrm{C}$ overnight. For each analysis $0.2 \mathrm{~g}$ of sample was used. The samples were degassed at $77 \mathrm{~K}$ for 3 hours, the surface area was then measured by $\mathrm{N}_{2}$ absorption and desorption isotherms at this temperature. This analysis was also run by QUB ASEP facility.

\subsubsection{Imaging}

SEM analysis was performed on diatom samples to ensure their morphology remained intact after heat treatment. It was also performed on scaffolds after 3D printing to analyse the surface of the scaffolds. A FEI Quanta FEG - Environmental SEM from Oxford EX - ACT was used in this study. Before the samples were loaded into the SEM, samples were gold coated using a sputter coater. The samples were coated for 40 seconds, and imaged in the SEM under a high vacuum at $20 \mathrm{kV}$ and with a 3.0 spot. The filaments and scaffolds were also imaged under an optical microscope (Olympus Stereo Microscope).

\subsubsection{Mechanical Testing}

The filaments were tested using an Instron 5564 universal tensile tester. Samples were prepared by cutting segments from the filament every $30 \mathrm{~cm}$. These were compressed at $180{ }^{\circ} \mathrm{C}$ at a pressure of 10 bar for 90 seconds in a Collin platen press to create a polymer sheet of thickness of approximately $1 \mathrm{~mm}$. Dumbbells were then cut from the sheet in accordance with the British Standard ISO 527-2-1BA. An extensometer was used to measure the strain within the gauge length. A constant speed of $1 \mathrm{~mm} / \mathrm{min}$ was applied to deform the samples. Scaffolds were compression tested using a Zwick/Roell Z100 Instrument. A preload 
of $150 \mathrm{~N}$ was applied and loaded at a cross-head speed of $2 \mathrm{~mm} / \mathrm{min}$. All samples were tested

248

250

251

252

253

254

under dry conditions. The energy under the stress-strain curve was determined using the trapezoidal rule in MATLAB R2020a to determine the energy absorbed by the filaments. The calculations were confirmed in excel by fitting a high order polynomial trend and integrating the polynomial function.

\subsubsection{Rheology}

The viscoelastic properties of the filaments were assessed using rheology. Polymer discs with the diameter of $2.5 \mathrm{~cm}$ were cut from the polymer sheets that were prepared for mechanical testing (see section 2.3.5). A TA Rotational Rheometers ARG2 was used in this study. In this study, two methods were taken to study viscosity. Method 1: The first used a frequency sweep approach to predict the zero-rate viscosity from the change in frequency from $100 \mathrm{~Hz}$ to $0.1 \mathrm{~Hz}$ at the respective print temperatures, Table 2. The zero-rate viscosity was predicted using Carreau-Yasuda Model $^{34}$ (Eq. 2) that applied the Cox-Merz rule ${ }^{35}$.

$$
\mu_{e f f}(\gamma)=\mu_{i n f}+\left(\mu_{0}-\mu_{i n f}\right)\left(1+(\lambda \gamma)^{2}\right)^{\frac{n-1}{2}}
$$

Where,

$\mu_{0}, \mu_{\text {inf }}, \lambda$ and $n$ are the material coefficients.

$\mu_{\text {eff }}=$ viscosity at effective shear rate (Pa.S)

$\mu_{0}=$ the zero-rate viscosity (Pa.S)

$\mu_{\text {inf }}$ is the viscosity at the infinite shear rate (Pa.S)

$\lambda=$ relaxation time $(\mathrm{s})$

$n=$ power index.

$\gamma=$ shear rate $\left(s^{-1}\right)$

Method 2: The second approach used a change in temperature from 130 to $250^{\circ} \mathrm{C}$ at a constant frequency of $1 \mathrm{~Hz}$ to study the changes in viscosity.

\subsection{Statistics Analysis}


IBM SPSS version 25.0 was used for the statistical analysis to determine the variance

278

279

280

281

282

283

284

285

286

287

(ANOVA) between different groups and factors in different studies. One-way ANOVA was performed on strut width, tensile, compression test data and TGA thermal data. For all statistical comparisons a Tukey post-hoc test was used. Normality was checked by ShapiroWilks's test $(p>0.05)$.

\section{Results}

\subsection{Diatom Silica}

The removal of the organics was verified using TGA, shown in Fig 2a/Table 3. A slight mass loss was observed up to $200^{\circ} \mathrm{C}$ in all 3 treatments, which is a result of the dehydration of the powders. Thereafter, a significant mass loss $(\approx 20 \%)$ was observed between 200 and $500^{\circ} \mathrm{C}$ in AT and WT treatment groups, which is indictive of organic matter, which was not observed in the heat-treated sample (HT). Relatively few studies have reported on the thermal stability or pyrolysis of marine or freshwater diatoms ${ }^{36,37}$. There are multiple factors that influence the organic to inorganic ratios, most importantly the availability of silica ${ }^{38}$ and evolution history, as over time diatoms will become less siliceous. Also environmental factors including light which influences valve formation ${ }^{39}$, and $\mathrm{pH}$, salinity and temperature that effect cell division ${ }^{40-42}$. These environmental stresses will impact lipid storage and metal uptake thus resulting in variation in the organic to inorganic ratio. Therefore, direct comparison of percentage mass loss to other studies is ineffective. However, the thermal degradation profile trends are comparable to other studies. Sprynskyy et al., TGA profile of Pseudostaurosira trainorii diatoms after purification showed a similar trend to AT and WT treatment groups in this study, where the thermal decomposition of residual organics was 
300 reported to be between 199 to $576^{\circ} \mathrm{C}^{36}$. The mass loss which occurred between 576 and

$301800^{\circ} \mathrm{C}$ in their study was attributed to dehydroxylation of free hydroxyl groups within the

302 biosilica structure. A similar mass loss was observed in our data, which was most

303 pronounced in the AT treatment group, indicating the same reaction has taken place. In

304 terms of the actual biosilica thermal stability, Arasuna et al., report diatom biosilica from

305 Chaetoceros calcitrans was thermally stable up to $800^{\circ} \mathrm{C}$ using $x$-ray different analysis, but

306 thereafter changed from amorphous silica to a similar structure to that of quartz ${ }^{37}$. They

307 also confirmed that organics were effectively removed at temperatures below $600^{\circ} \mathrm{C}$, which

308 supports our findings. The purification method used in this study appears to have been

309 slightly more effective than that of the study by Sprynskyy et al., ${ }^{36}$, that reported a higher

310 residual mass loss of $11.5 \%$ after purification treatment, as opposed to $4.8 \%$ at $800^{\circ} \mathrm{C}$ that

311 was observed in this study.

313 The reduction in organics with respect to treatments correlates directly to an increase in

314 specific surface area (Table 3 ) which suggests that that the pores of the diatoms are

315 becoming unblocked as the organics are being removed, thus creating more surface area.

316 The specific surface area of the purified frustules of $58.80 \mathrm{~m}^{2} / \mathrm{g}$ was found to be in the within

317 the range (16.9 to $100 \mathrm{~m}^{2} / \mathrm{g}$ ) of those reported in the literature ${ }^{10,36}$. The same trend was

318 observed in the CHNS analysis (Table 3), whereby a reduction in carbon and nitrogen was

319 apparent. Since carbon is associated with the organics in the diatoms ${ }^{43}$, the reduction in

320 carbon with respect to treatments indicates the successful removal of organics, thus

321 verifying the TGA results. The higher nitrogen levels in the AT treatment, will be a result of 
the nitric acid pre-treatment by St. Cloud State. After the subsequent treatments, WT and

$323 \mathrm{HT}$, the level was reduced from $1.91( \pm 0.39) \%$ to less than $0.30 \%$.

325 The SEM results shown in Fig $2 \mathrm{c}$ to $\mathrm{g}$ indicate that the frustule valves remained intact after

326 heat treatment (Fig. 2c and g). Untreated diatoms contain two-diatom valves interlocked to

327 form frustules and are held together with a girdle band which is bound tightly by organics as

328 shown in the schematic in Fig. $2 \mathrm{~b}$. The outer surface has a nanopatterned pore structured surface around the outer edge (Fig $2 c$ to e), whereas the inside of the valve has a recessed segmented pattern (Fig 2f). Once the organics are removed, the frustules mainly separate, although some retain their original form, as shown in Fig 2e. The outside and inside of the valves form two petri-like discs that make up the frustules as shown in Fig $2 c$ to $f$. This species of diatoms also contains spikey pointed spines around the outer edge (Fig $2 \mathrm{c}$ and d).

334 The remaining biosilica after the organics has been removed was a mixture of valves, girdle bands and frustules as shown in Fig $2 \mathrm{~g}$. The average particle size of the $C$. meneghiniana valves used in this study were found to be between 15 and $20 \mu \mathrm{m}$. It is noteworthy to mention, that the bulk mix also included silica girdle bands (Fig $2 \mathrm{f}$ and g) which were impossible to separate from the mixture after thermal decomposition. As evident from the SEM images, the diatom particles are flat disc like particles as opposed to granules like the aspect ratio to that of the Bioglass particles. 
a)

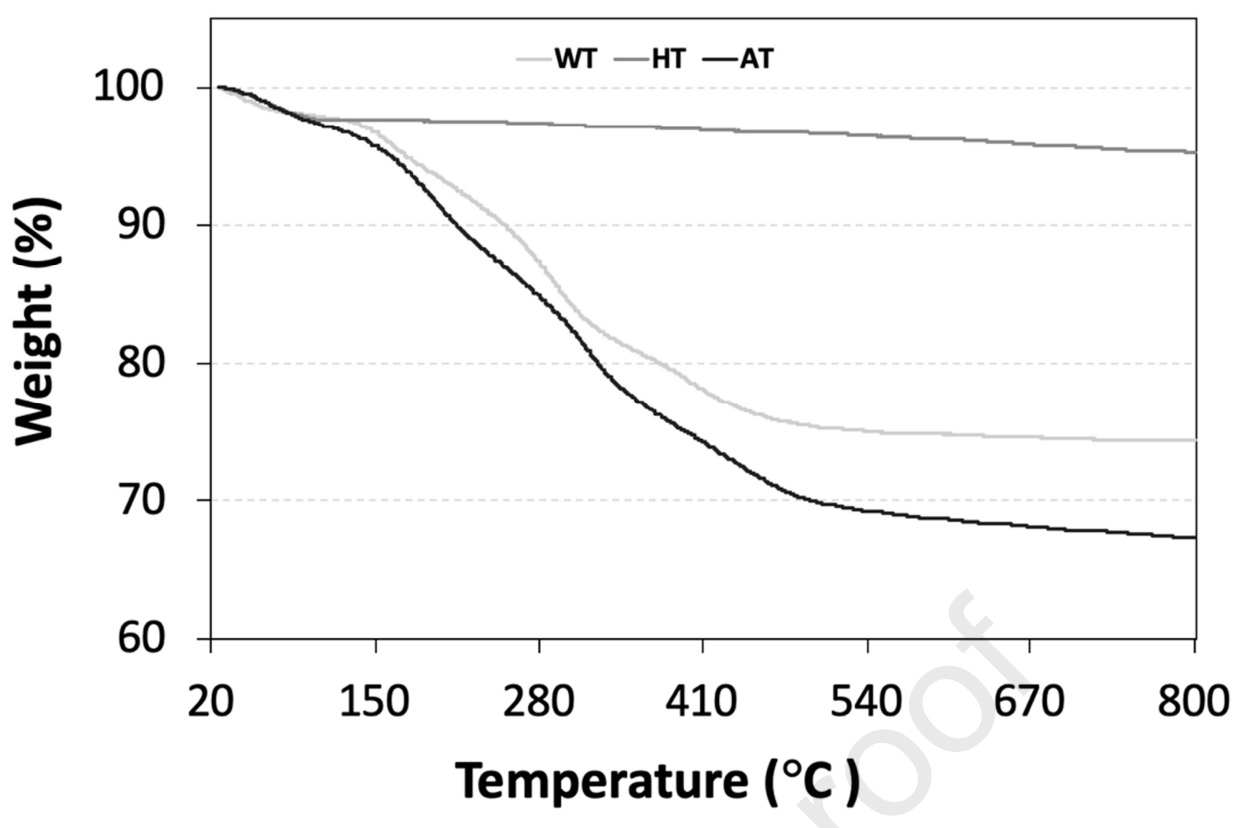

b)
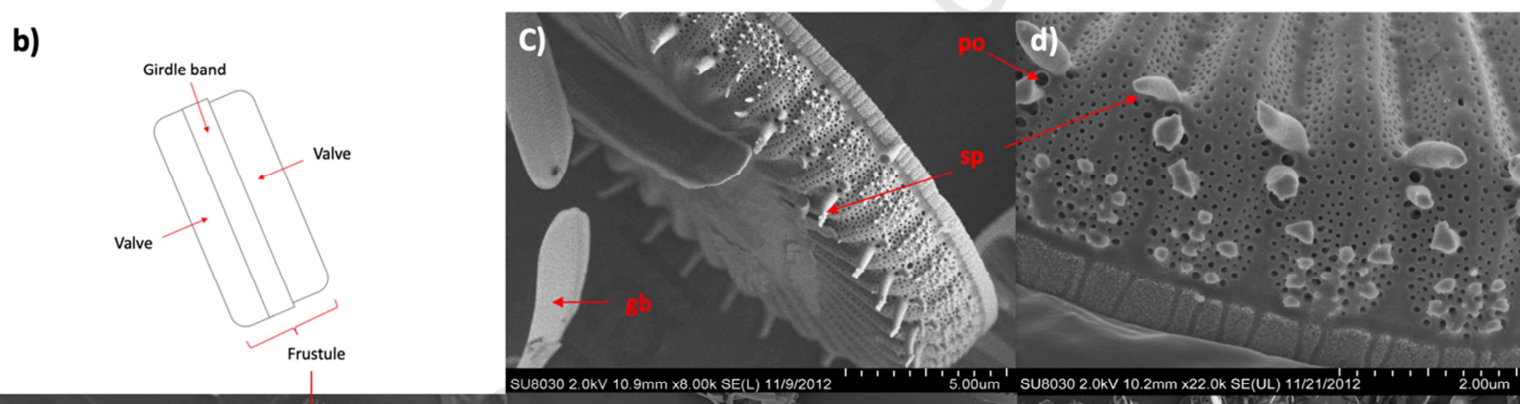

e)

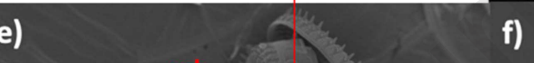

f)
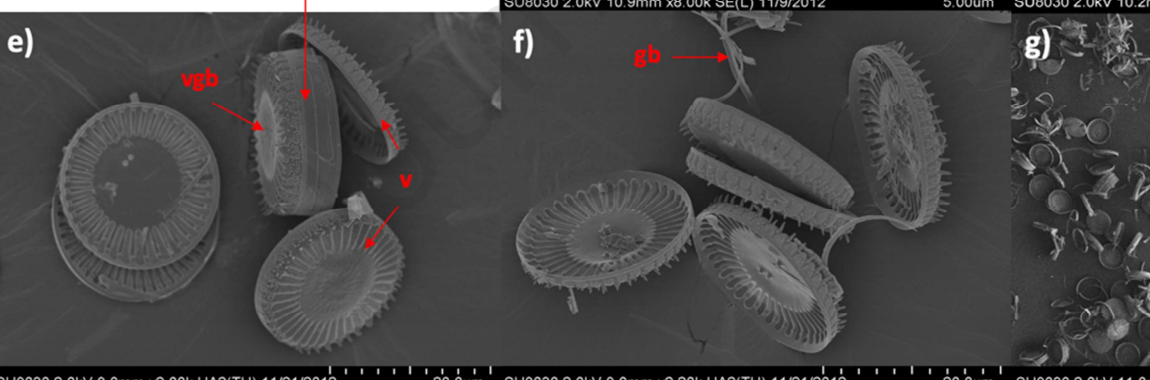

Figure 2: Profiling the removal of organics from diatoms (a) thermogravimetric analysis after each treatment (b) schematic of diatom frustule and scanning electron microscope of frustules after heat treatment (c) diatom valve (d) zoomed edge of diatom valve (e) valves and frustule intact (f) valves and gridle bands and (g) deconstructed diatom frustules. Abbreviations: (po) pore openings, (sp) spines, (gb) gridle band, (v) valve and (vgb) valve with girdle band intact.

\begin{tabular}{|c|c|c|c|c|c|c|}
\hline \multirow[b]{2}{*}{ Treatments } & \multirow{2}{*}{$\begin{array}{c}\text { TGA } \\
\text { Mass Loss at } \\
800^{\circ} \mathrm{C} \\
(\%)\end{array}$} & \multirow{2}{*}{$\begin{array}{c}\text { BET } \\
\text { Specific } \\
\text { surface Area } \\
\left(\mathrm{m}^{2} / \mathrm{g}\right)\end{array}$} & \multicolumn{4}{|c|}{ Elemental } \\
\hline & & & C (\%) & H (\%) & N (\%) & S (\%) \\
\hline 1 & 32.66 & 11.57 & $14.52( \pm 2.57)$ & $2.38( \pm 0.28)$ & $1.91( \pm 0.39)$ & $<0.30$ \\
\hline 2 & 25.60 & 11.93 & $12.17( \pm 3.16)$ & $3.20( \pm 1.41)$ & $1.86( \pm 0.26)$ & $<0.30$ \\
\hline 3 & 4.8 & 58.80 & $<0.30$ & $0.46( \pm 0.14)$ & $<0.30$ & $<0.30$ \\
\hline
\end{tabular}

Table 3: Diatom physiochemical profiling analysis of purification process. 
371

373

374

375

376

377

378

379

380

381

382

383

384

385

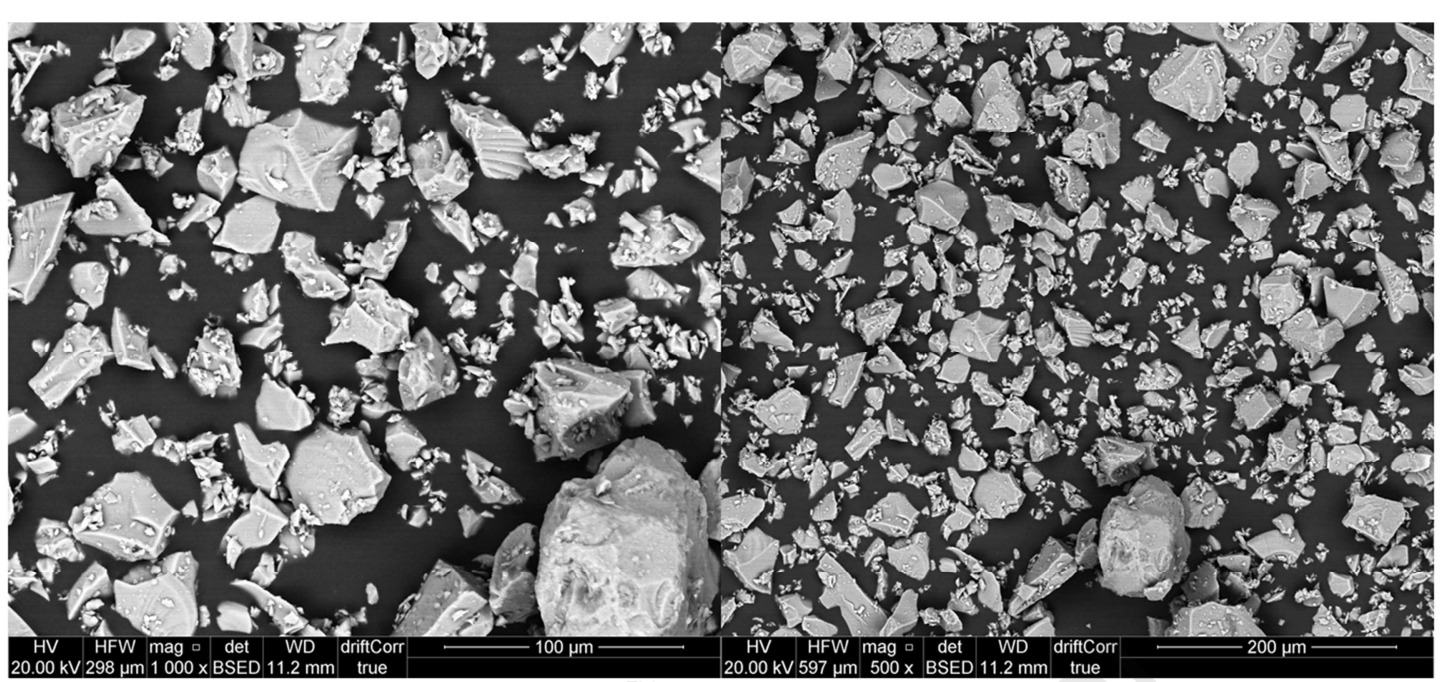

Figure 3: SEM images of Bioglass 45S5 (Sylc ${ }^{T M}$, Research Ltd, London, UK) from Denfotex at different magnifications

\subsection{Filaments}

\subsubsection{Filament Processing}

Fig. 4a shows optical microscopy images of the extruded filament. A slight variation of colour was observed between filament groups, with the darkest filament being $5 \%$ DiatomsPDLGA. However, this was a result of the colour of the diatom filler which is offwhite/cream in colour as opposed to decolourisation from processing. At higher concentrations the additive is more visible causing greater decolourisation. Bioglass powder is brilliant white due to light scattering so the filaments were whiter in appearance (Fig 4a). None of the filaments showed signs of polymer degradation which is typically evidenced by either discoloration of the polymer or increased brittleness.

During processing, the draw-off speed of the extruder was adjusted to achieve the desired filament diameter of $1.75 \mathrm{~mm}$. However, a slight variation did occur between filament groups as reported in Fig $4 \mathrm{~b}$. For both the groups with diatoms biosilica powder fillers, the diameter was found to be slightly under the desired diameter, in the range of 1.69 to $1.72 \mathrm{~mm}$, whereas the diameters of pure-PDLGA and 5 wt \% Bioglass-PDLGA filaments were 
390 found to be slightly higher, with diameters of $1.79(+0.07 /-0.12)$ and $1.83(+0.1 /-0.16) \mathrm{mm}$

391 respectively. In addition, significant variation was observed in the 5 wt \% Bioglass-PDLGA

392 filament along its length. Sections of this filament were too wide for the printer and had to

393 be cut out and discarded. The pure-PDLGA filament was slightly wider than that achieved by

394 Little et al., of $1.75(+0.15 /-0.08)^{18}$ but still within specification for the 3D printer. TGA was

395 used to check the ceramic content in the filaments and its distribution along the total

396 filament length. The results show (Fig 4b) that this blending method was effective for

397 diatom filler but not the Bioglass filler. The samples were heated up to $800^{\circ} \mathrm{C}$. The rationale

398 being, that the PDLGA should melt then decompose below $800^{\circ} \mathrm{C}$, whereas the ceramics

399 should not decompose below $1000^{\circ} \mathrm{C}$ (silica usually melts at $\left.1,200^{\circ} \mathrm{C}\right)^{37,44,45}$. The ceramic

400 fraction in the filaments was calculated as per equation 1. The filler mass of diatom-PDLGA

401 filaments was found to be $1.22( \pm 0.46) \%$ and $4.56( \pm 0.21) \%$ for 1 and 5 wt \% blends

402 respectively. Whereas, the 5 wt \% Bioglass-PDLGA filament was found to have significant

403 variation along its length resulting in filler average concentration of $5.01( \pm 2.02) \%$. The

404 highest amount of Bioglass was found to be $8.91( \pm 0.77) \%$ and the lowest amount was

405 found to be $3.45( \pm 0.31) \%$. The large standard deviation denotes an uneven distribution

406 along the filament length which was potentially caused by agglomeration or variation of the

407 particle size (Fig. 3) of Bioglass powders used. This supports the findings from the filament

408 diameter measurements, which found the greatest variation to be in the Bioglass filament.

409 Rajzer et al., also reported the dispersion of Bioglass in their composites to be

410 heterogeneous with some agglomeration of particles ${ }^{46}$. Better premixing, such as turbo

411 blending or a more uniform particle size could alleviate particle agglomeration of Bioglass.

412 However, in a twin-screw extruder, the combination of temperature and the mechanical

413 rotation of the screws in the melting zone of the extruder (Fig 1a), should disperse the 
414 agglomerated particles within the polymer ${ }^{20}$. Further work is required to better understand

415 the cause of particle agglomeration of Bioglass in PDLGA during processing.

416

417

418

419

420

421

422

3.2.2 Filament Mechanical Data

a)
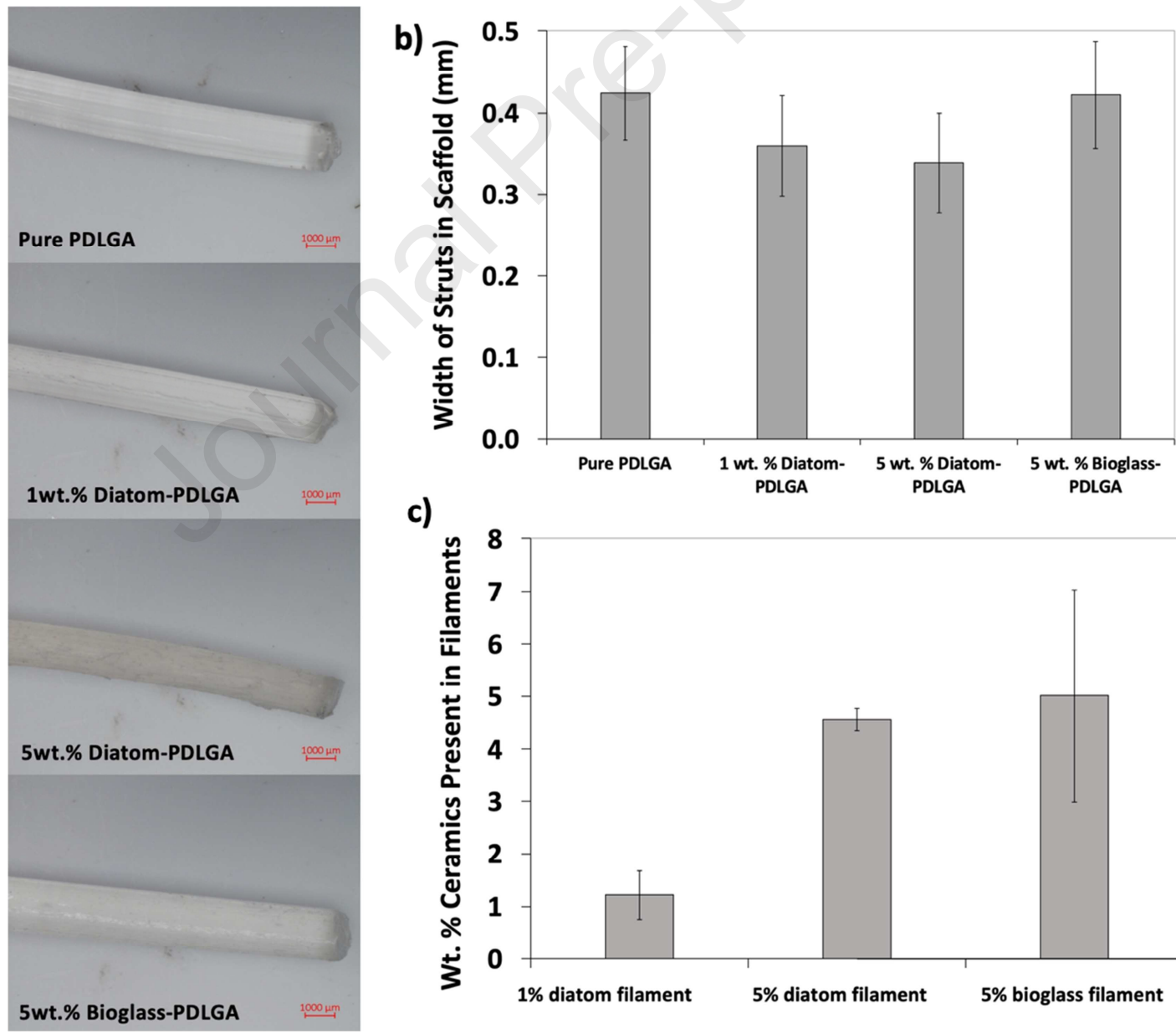

c)

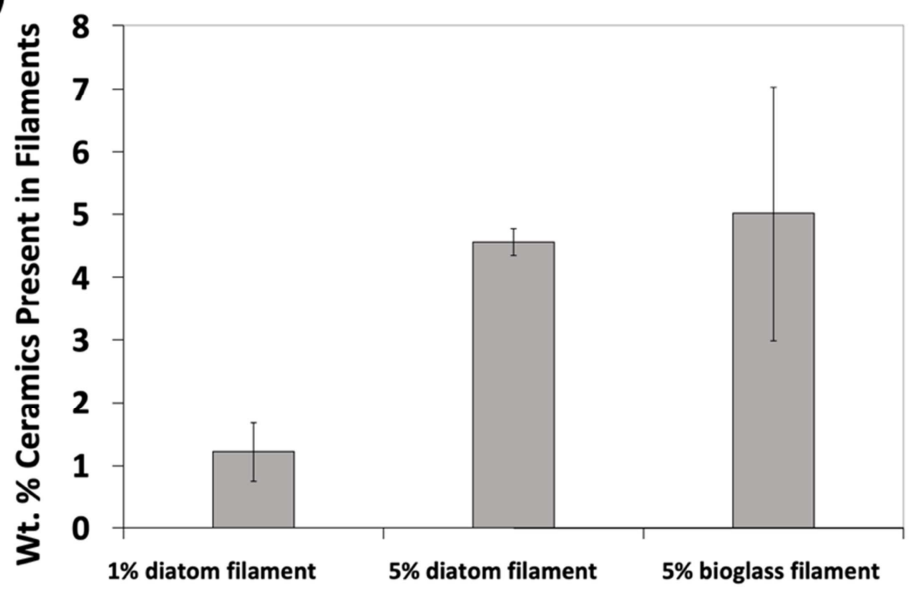

Figure 4: Filament profiling (a) optical microscopy images of extruded filaments, (b) filament diameter (c) ceramic additive wt. \% by TGA. Error bars for $3 b$ represent the max and min diameter, where $n=10$. 
430

431

432

433

434

435

436

437

438

439

440

441

442

443

444

445

446

447

448

449

450

451

452

453

454

455

456

457

458

459

460

461

462

463

464

465

466

467

468

469

470

471

472

473

474

475

476

477

478

479

480

481

482

483

484

485

486 a) $\square$ Ultimate Tensile Strength (MPa) $\mathbf{\Delta E l o n g a t i o n ~ a t ~ B r e a k ~ ( \% ) ~}$

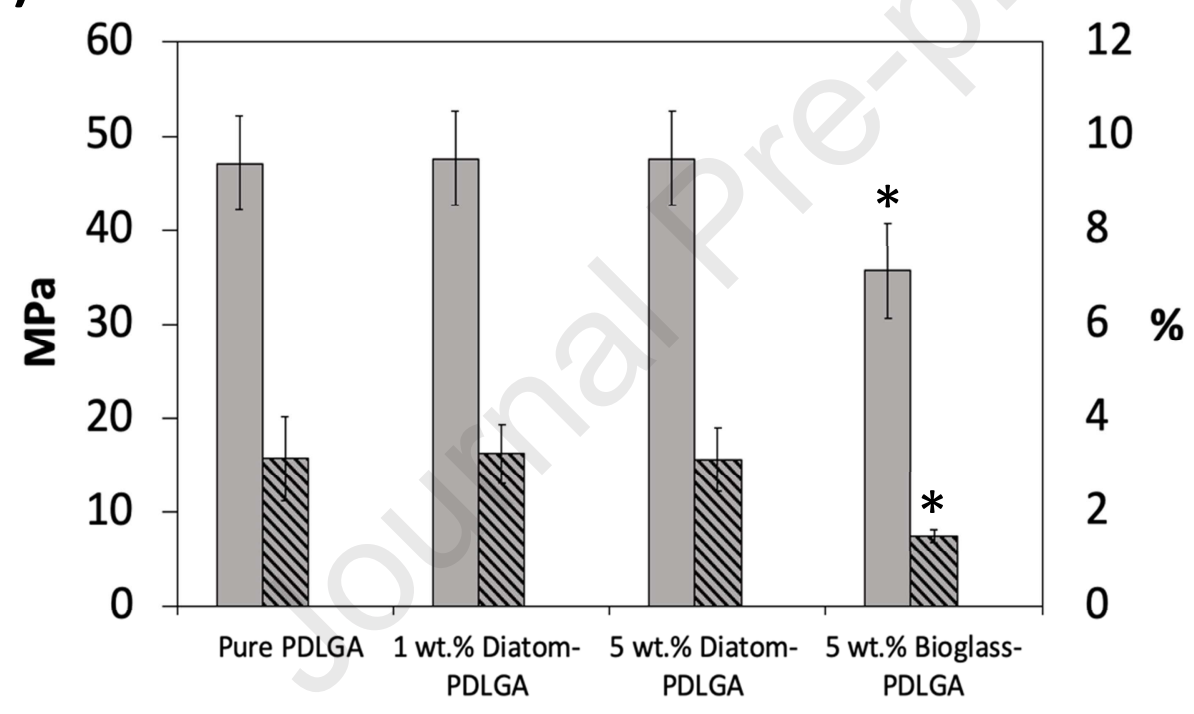

b)

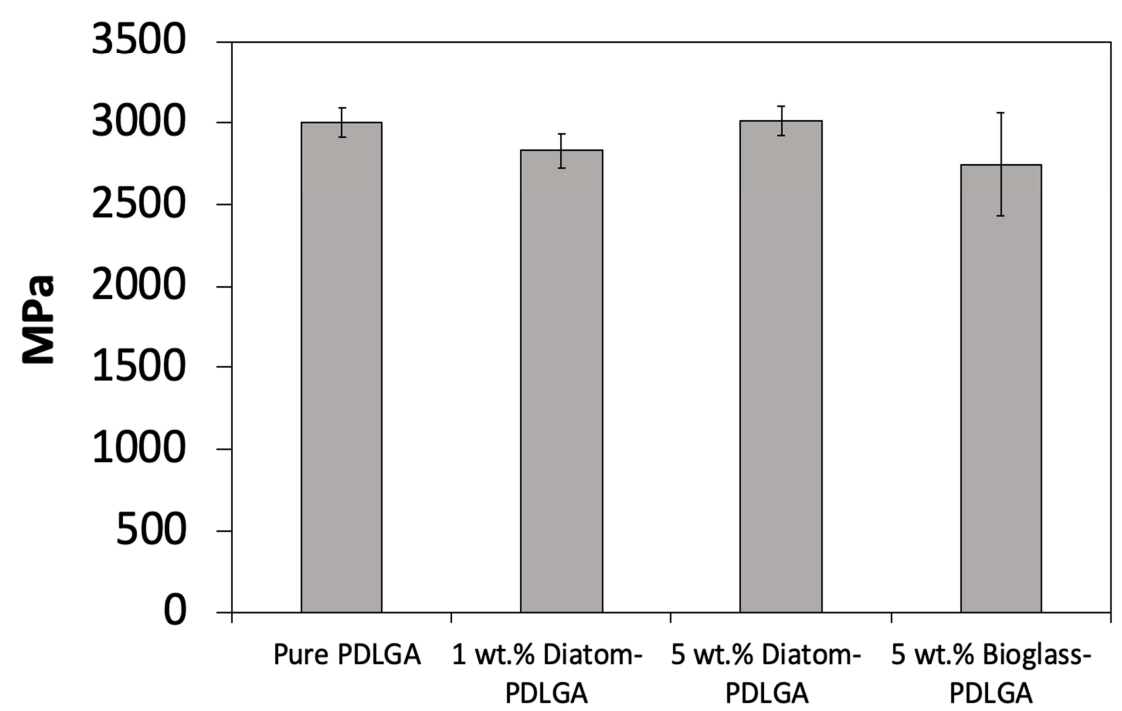


Figure 5: Mechanical data for filaments (a) for ultimate tensile strength and elongation at break (asterisks indicate statistically significant difference) and (b) Young's modulus. (c) Toughness. Error bars represent SD where $n=5$, statistical significance, $p \leq 0.05$

47.12 ( \pm 1.59 ) $\mathrm{MPa}$ (Fig 4a), which was similar to 1 and 5\% wt \% diatom-PDLGA filament that

511 therefore, strength will improve with good bonding between particles ${ }^{47}$. Therefore, points for potential stress transfer. In this study, the bonding between particles is mainly physical (i.e. surface roughness of the particles interacting with the matrix), as no chemical

515 linker has been used. However, some chemical interaction is also likely between the hydroxyl groups of the PDLGA and the surface chemistry of the silica. Hydrogen bonding

517 between $\mathrm{C}=\mathrm{O}$ groups in the PDLLA with the surface $\mathrm{Si}-\mathrm{OH}$ groups is also likely to occur;

518 similar interactions have been reported in the literature for composites that have been dry

519 blended prior to processing ${ }^{48}$. Both of these particle matrix interactions rely on surface-to-

520 surface contact. It seems likely that stress transfer is occurring but, given that no significant 
PDLGA filament groups, it can be concluded that this is minimal and likely to be negated by changes to the polymer itself, such as processed-induced degradation.

The 5wt. \% Bioglass-PDLGA filament was found to have the lowest UTS at 35.71 ( \pm 1.50 ) $\mathrm{MPa}$, and differed statistically in the post-hoc analysis $(p<0.05)$. The addition of diatoms to PDLGA at both $1 \%$ and $5 \%$ made no significant difference to the elongation of the filaments. Whereas, the addition of Bioglass to PDLGA was found to significantly reduce the filament's ductility when compared to pure-PDLGA, $p=0.05$ and both diatom groups, $p=0.03(1 \%)$ and $p=0.05(5 \%)$. Brittleness in the Bioglass filaments would suggest thermal degradation of the polymer via a chain scission mechanism ${ }^{18}$, which supports the findings of Simpson et al., ${ }^{5}$

The Young's Modulus of the filaments were found to be in the range of 2,700 and $3,000 \mathrm{MPa}$

534 (Fig 5b) but no significant difference in Young's modulus between filament groups was found.

The 5wt. \% Bioglass-PDLGA filament was found to have the greatest variation in modulus (2746.44 ( \pm 314.96) MPa) compared to the other groups. This is consistent with the other data. One of the contributing factors to the high variation in Young's Modulus in the Bioglass filament is most likely to be a result of the uneven distribution of the Bioglass powder particles (Fig. 3) as previously discussed.

542 The toughness (defined as the energy to break of the filaments) of the 5 wt \% diatom-

543 PDLGA filament was found to be significantly higher $(p<0.05)$ than the other filament groups

544 tested. The $5 \mathrm{wt} \%$ diatom-PDLGA filaments were found to absorb $45 \%$ more energy than

545 both the pure-PDLGA and 1 wt \% diatom-PDLGA filaments and just under $80 \%$ more energy 
than 5wt. \% Bioglass-PDLGA filaments. Both pure-PDLGA and 1 wt \% diatom-PDLGA

547 filaments were also found to absorb significantly more energy than the $5 \mathrm{wt}$. \% Bioglass-

548 PDLGA filaments. However, no significant difference was observed in the energy absorbed

549 between pure-PDLGA and 1 wt \% diatom-PDLGA filaments. Although changes in energy

550 absorption could have been influenced by the morphology of the incorporated particles

551 (high surface to volume ratio in terms of the disc-like shape of diatoms), it is also plausible

552 that the differences observed were influenced by the extent of thermal degradation of the matrix polymer.

Strength and fracture toughness are two of the most important properties of a composite materia $\left.\right|^{50}$. Although the addition of the fillers did not enhance the UTS of the PDLGA, it did not compromise it either. However, one of the significant findings is the increase in toughness in the PDLGA with the addition of $5 \%$ diatoms. High toughness is important to

559 reduce microdamage crack formation and development that can occur in implanted 560 scaffolds through load-bearing activities ${ }^{51}$ or potential manufacturing defects. Ceramic561 polymer composite materials have been well studied in several fields, and it is well known that several factors can affect the tensile strength of a composite material. These include particle concentration, distribution of particles within the matrix, physical attributes of the particles (size, morphology profile) and the matrix-particle interfacial properties ${ }^{11,52}$. It was

565 hypothesised that the unique topographical features of diatom frustules could potentially enhance the interfacial bond strength between the matrix and the filler thus enhancing the

567 mechanical properties of the composite. However, the results did not support the 568 hypothesis at the concentrations tested. The concentrations of the fillers were kept 569 deliberately low as the addition of ceramics particles in higher concentrations $(>10 \%)$ have 
570 previously been reported to reduce the accuracy of 3D printed scaffolds ${ }^{11}$. In addition, the

571 diatom frustules were considered to have exceptional mechanical properties with a Young's

572 modulus of $22.5 \mathrm{GPa}$ which is similar to cortical bone $(\approx 20 \mathrm{GPa})$, owing to their unique

573 morphologies and complex hierarchical structures ${ }^{10,53}$. A further point to consider is the

574 possibility of fragmentation of the particles during processing due to the high shearing

575 forces of the twin-screw extrusion. Such damage would have reduced the aspect ratio of the

576 diatoms, a factor known to play a role in mechanical properties of clay-filler polymers ${ }^{54}$. The

577 effect of twin-screw extrusion on the particle size of ceramic particles, therefore, could be

578 investigated in future work in this area.

579 In this study, the mechanical properties were measured in a dry state to determine an

580 understanding of the fundamental mechanical properties of these composite materials. To

581 validate the scaffolds for their application in bone tissue, further degradation studies are

582 required to assess their temporal mechanical behaviour in a wet environment.

584

3.2.2 Rheology of Filaments

585

a)

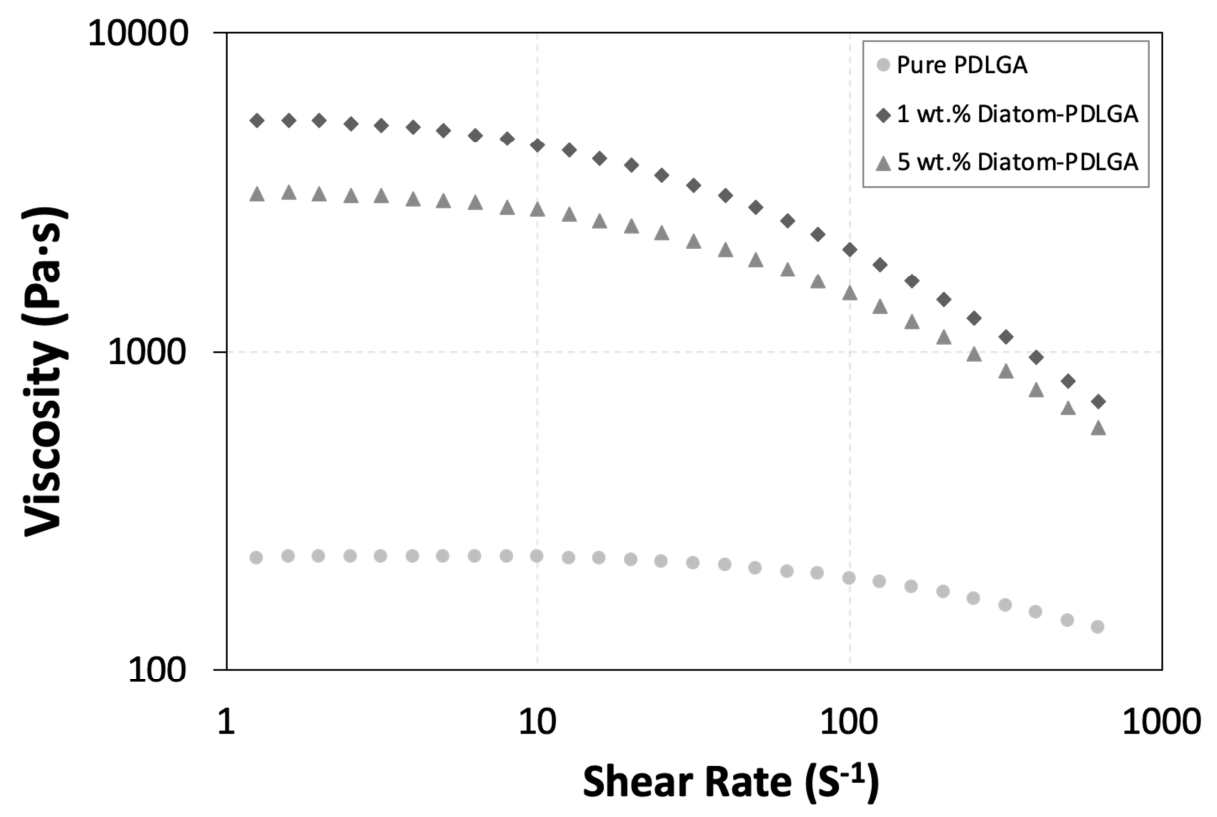


b)

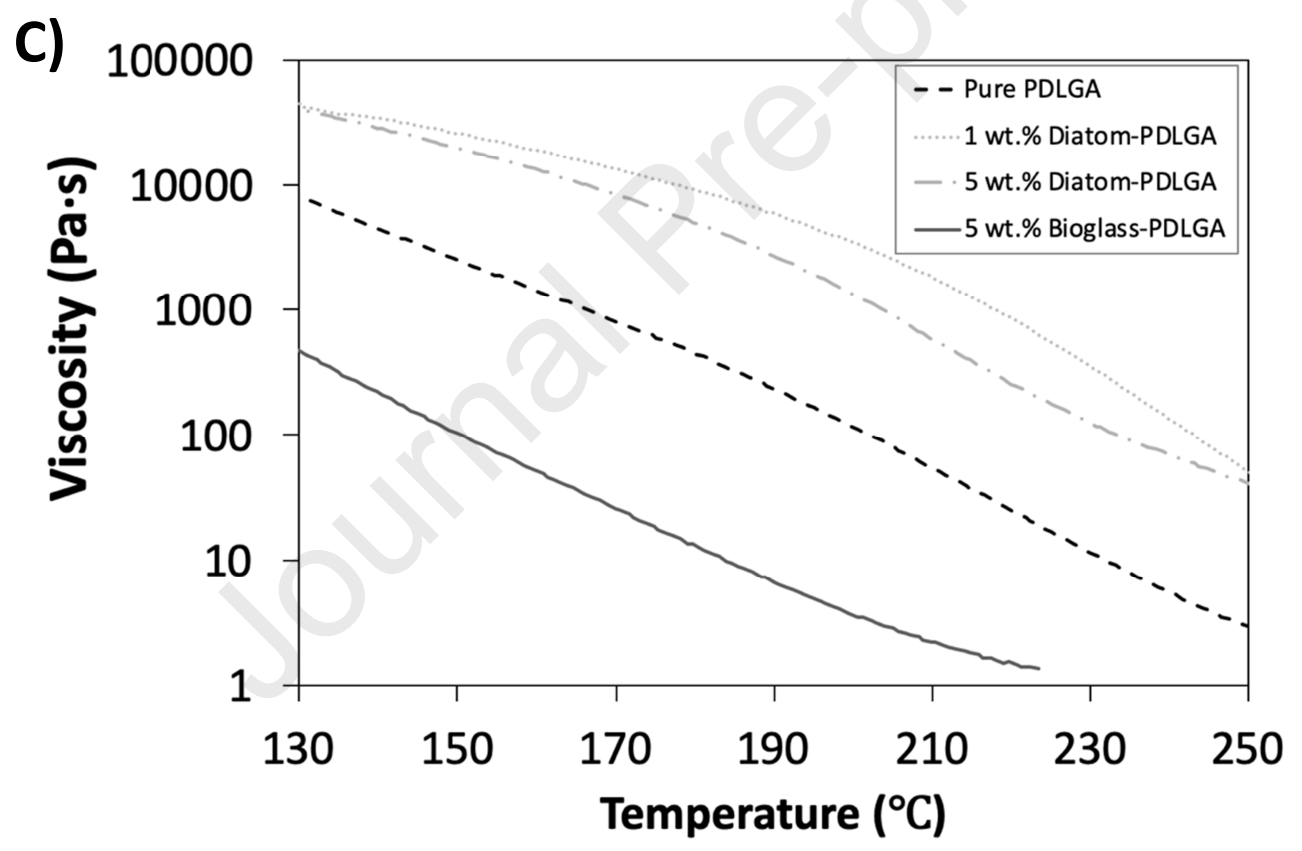

634 results are shown in Fig. 6. The frequency sweep on the second oscillation experiment (Fig 6

635 a) was selected to study the viscosity changes in the polymers from $100 \mathrm{~Hz}$ to $0.1 \mathrm{~Hz}$, which

636 is equal to shear rates from $628.3 \mathrm{~s}^{-1}$ to $0.628 \mathrm{~s}^{-1}$. The experiment (Fig 6a) was performed at 637 a fixed temperature of $190^{\circ} \mathrm{C}$. The slow shear rate setting replicates the 3D printing process 
without applying any shear strength on filament. The optimum temperature to print Pure PDLGA filaments was found to be $190{ }^{\circ} \mathrm{C}$, however, at this temperature both $1 \mathrm{wt} \%$ and 5

640 wt \% diatom-PDLGA filaments were difficult to print and blocked the printer nozzle. They

641 required much higher print temperatures of 220 and $225^{\circ} \mathrm{C}$ respectively. This is confirmed

642 by the results from the rheology in Fig 6a showing that both 1 wt \% and 5 wt \% diatom-

643 PDLGA had significantly higher viscosities of magnitudes 25 (1 wt \%) and 15 (5 wt \%) times

644 higher than pure-PDLGA. This explains the printing difficulties experienced at $190{ }^{\circ} \mathrm{C}$ for

645 both diatom filaments. High viscosities would have resulted in pressure increase in the flow

646 of the melted polymer as it meets the constrained geometry of the print nozzle. Fig. $6 \mathrm{~b}$

647 summarises the zero-rate viscosity from the filaments at different temperatures correlating

648 to the actual temperatures used in the printing trials. The viscosities at 1 and $5 \mathrm{wt} \%$ diatom-

649 PDLGA were found to be 4729.3 ( \pm 1345.0) Pa.s and 3438.7 ( \pm 722.0 ) Pa.s respectively at $190^{\circ} \mathrm{C}$, which dropped to $703.3( \pm 180.7)$ Pa.s and $300.2( \pm 27.9)$ Pa.s at $220^{\circ} \mathrm{C}$ and $225^{\circ} \mathrm{C}$ respectively. The zero-rate viscosity of 5wt\% Bioglass-PDLGA was found to be $42.8( \pm 19.6)$

Pa.s at $165^{\circ} \mathrm{C}$, which was the lowest viscosity found within the groups. The final rheology experiment investigated the viscosity changes with respect to temperature (Method 2). The results are shown in Fig 6c. From the results an inverse relationship was observed with respect to temperature and viscosity, as the temperature increased the viscosity was found to decrease. According to this graph, the ideal print temperatures for printing 1 and $5 \mathrm{wt} \%$

657 diatom-PDLGA and 5 wt \% Bioglass-PDLGA is 235,220 and $140{ }^{\circ} \mathrm{C}$ respectively. For 1 wt \% diatom-PDLGA this was $15{ }^{\circ} \mathrm{C}$ higher than the final print temperature used, whereas for $5 \mathrm{wt}$ \% diatom-PDLGA and Bioglass-PDLGA it was lower (See Table 2). According to the literature,

660 the optimal print temperature of PDLGA has been reported to be $170^{31}, 180^{18}$ and $200^{\circ} \mathrm{C}^{32}$, 661 all of which were tested in the study but found unsuitable. The pure-PDLGA filaments in this 
662 study were found to print best at $190^{\circ} \mathrm{C}$. The discrepancies in temperature could be a result

663 of a number of factors, including degradation to the polymer during filament fabrication,

664 different printers or batch variation in the raw PDLGA. This $190^{\circ} \mathrm{C}$ print temperature for the 665 pure-PDLGA filaments was used as a reference temperature to print the other filaments.

666 Step-by-step intervals of $5{ }^{\circ} \mathrm{C}$ from $190{ }^{\circ} \mathrm{C}$ were used to determine their optimum print

667 temperature, which were found to be slightly outside of the range of the optimum print

668 temperature determined by the rheology results. Overall the rheology results show that the

669 composites can be melt processed successfully providing the print temperature is adjusted

670 to their melt point, which varies with respect to filler added.

671

672

673

674

675

676

677

678

679

680

681

682

683

684

685 
686

687

688

689

690

691

692

693

3.3 Scaffolds

694

695

3.3.1 Scaffold Processing 
a)
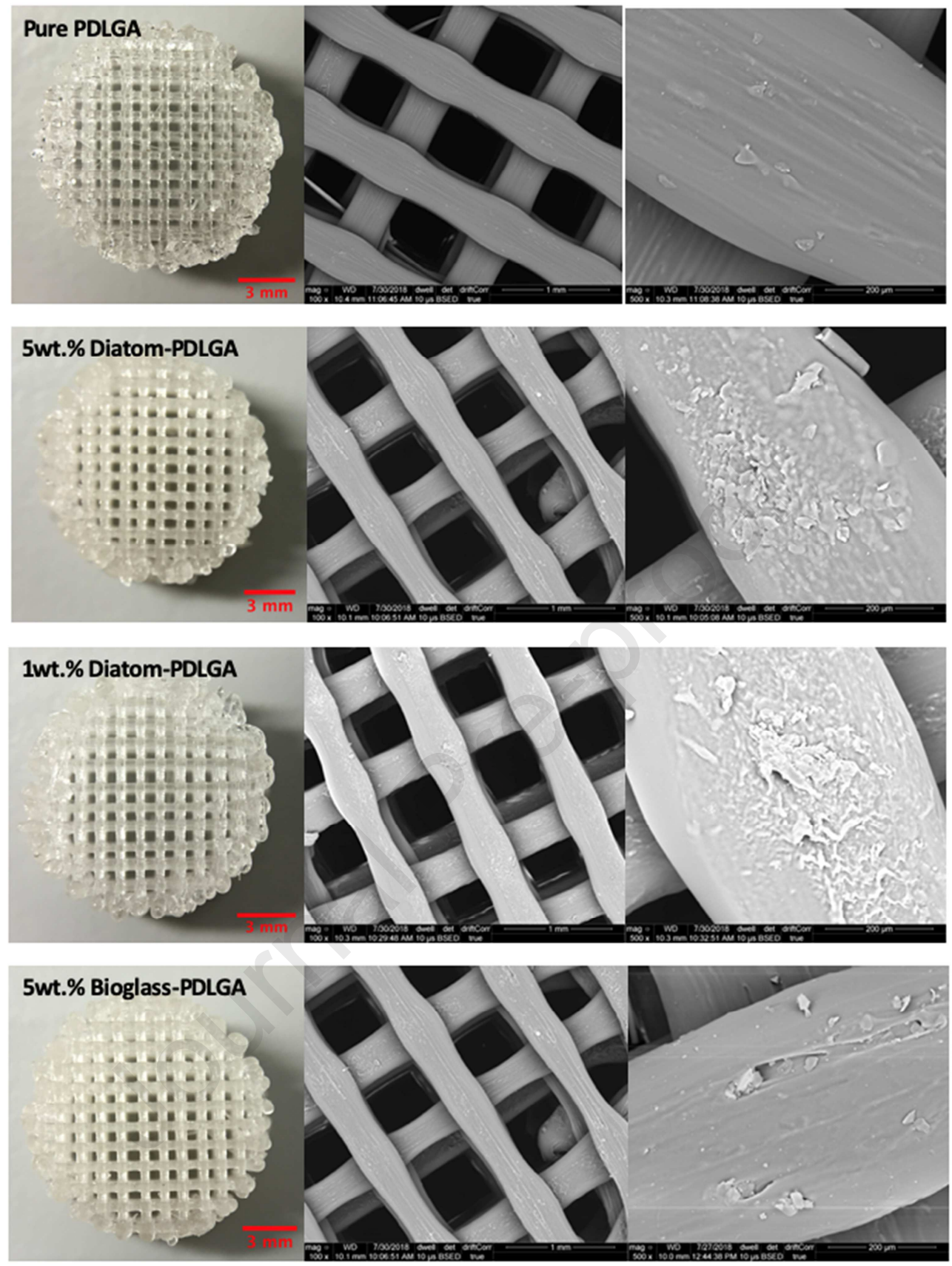
b)

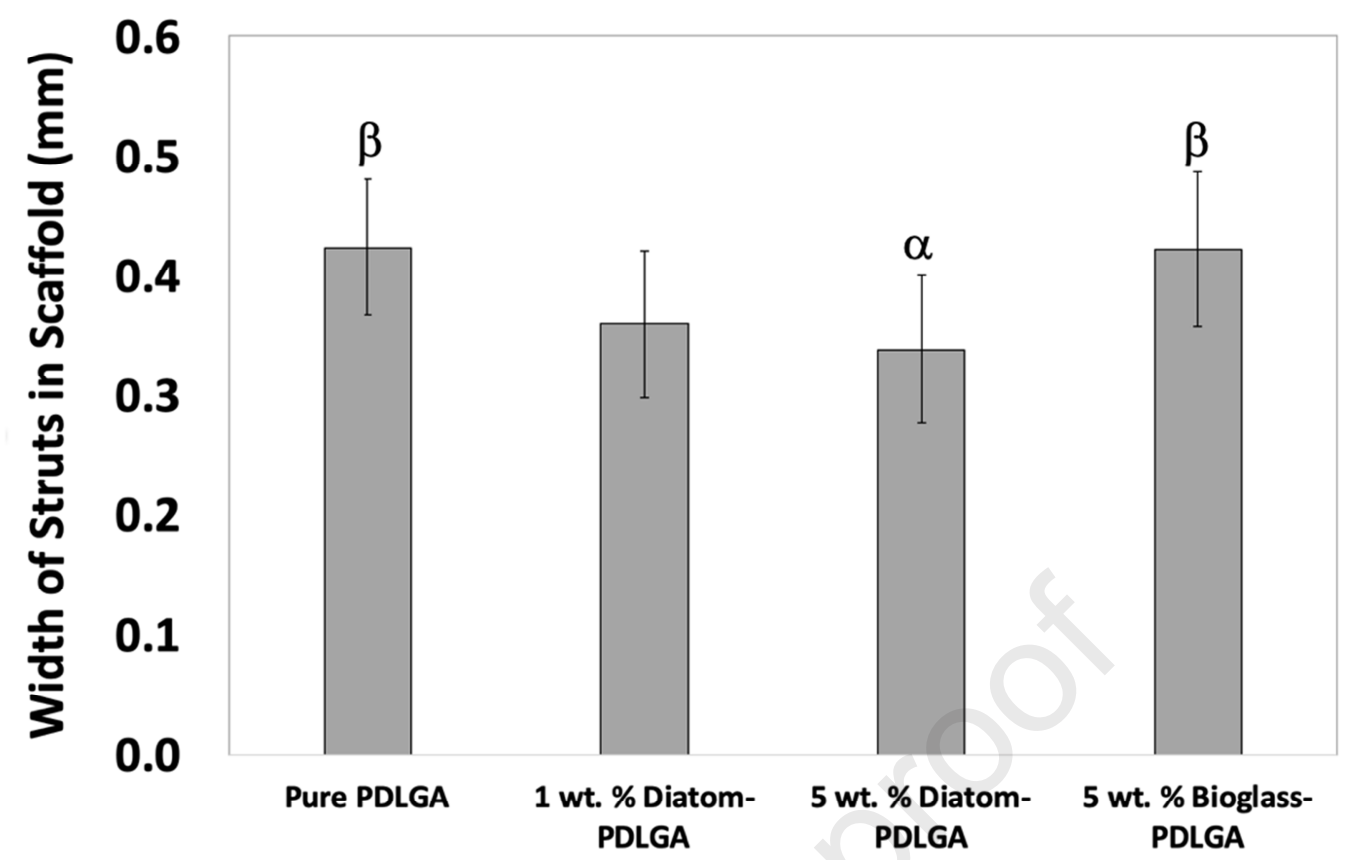

699

Figure 7: 3D printed scaffolds (a) optical microscopy and SEM images of top view surface of scaffolds and (b) the width of the struts in the scaffold determine from SEM images. Error bars represent SD where $n=3$, statistical significance 1-way ANOVA, $p \leq 0.005$ exist between ? and ? columns.

703

704

705

3D printing of all four filament groups proved successful as shown in Fig 7. A trial-and-error approach was taken to determine the optimum print temperature for each filament. The final temperatures used to print the filaments are shown in Table 1. The print temperature required for PDLGA with diatoms silica powder was significantly higher at 220 and $225^{\circ} \mathrm{C}$ for $190^{\circ} \mathrm{C}$. However, for the $5 \mathrm{wt}$. \% Bioglass-PDLGA filaments temperatures above $165^{\circ} \mathrm{C}$ were found to result in scaffolds that sagged and lost their shape.

713 After printing, striation marks were visible on all scaffold groups (visible on SEM images) of

714 the scaffolds in Fig 7a. This is a result of the extrusion of the polymers from the nozzle of the

715 3D printer. The surface roughness as a result of these striation is likely to be a positive

716 attribute for cell adhension ${ }^{55}$. The width of the struts was found to vary across all groups. 
717 Where the struts in the scaffold overlapped due to layering, they were found to be slightly

718 wider than in pore sections, as evident from the SEM images in Fig 7a. A significant

719 difference in strut width was observed between 5 wt \% diatom-PDLGA and both pure-

720 PDLGA and 5 wt \% Bioglass-PDLGA groups (Fig 7b).

721

722 Thermal processing is known to affect the molecular weight of polymers however, it is

723 unavoidable in these types of extrusion-based technologies that are used to fabricate

724 scaffolds. Processing time in the twin-screw extruder and 3D printer and the temperature in

725 both will affect the molecular weight of PDLGA as demonstrated by Little et al., ${ }^{18}$. In this

726 study, TGA analysis was used to assess the thermal stability of the scaffolds. In other words,

727 a material with a higher onset temperature is relatively more thermally stable than a

728 material with a low onset temperature. There is a linear relationship between the onset

729 temperature and the average molecular weight of the polymer ${ }^{56}$.

730

731

732

733

734

3.3.2 Thermal Properties of Filaments and Scaffolds
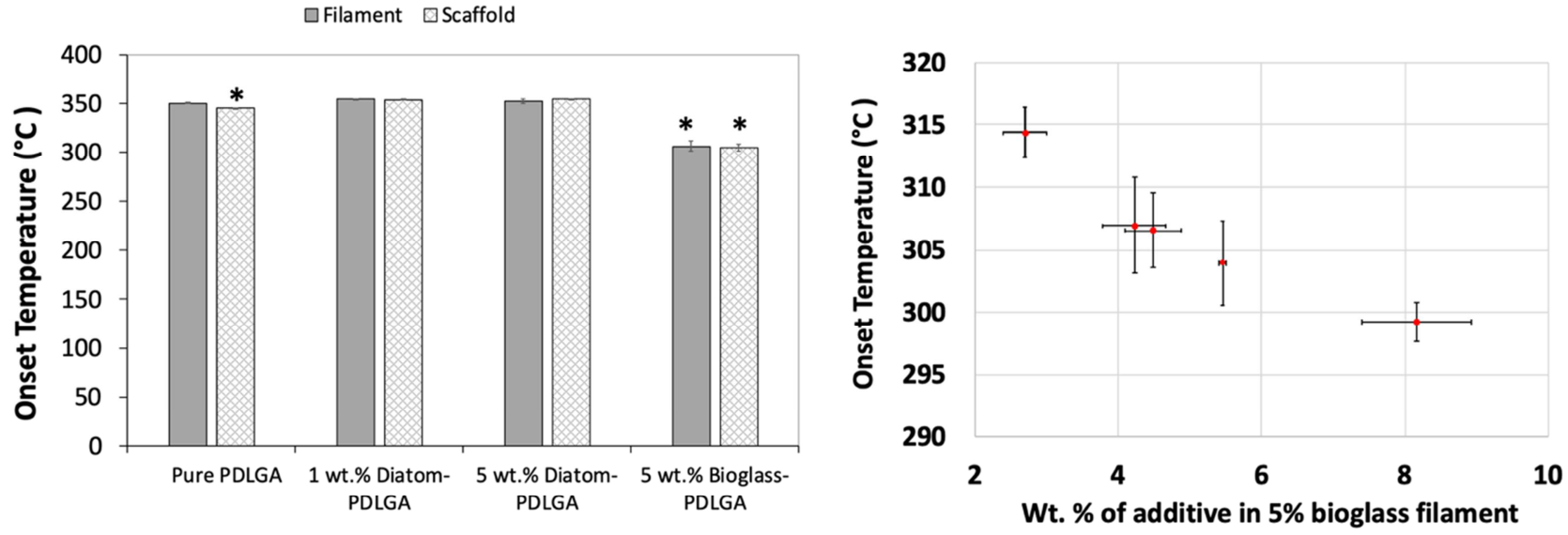
Figure 8: Thermal degradation of PDLGA polymer by TGA (a) after filament and scaffold fabrication (asterisks indicate statistically significant difference) and (b) additive versus onset temperature of Bioglass filament. Error bars represent SD where $\mathrm{n}=3$, statistical significance, $p \leq 0.05$.

740 The results for the thermal degradation study are shown in Fig 8. The onset temperature for pure-PDLGA for filaments, $350.13( \pm 0.69)^{\circ} \mathrm{C}$ and scaffolds, $345.24( \pm 0.25)^{\circ} \mathrm{C}$ was found to be lower than both diatom filler groups. For the filaments this difference was not found to be statistically significant for either the $1 \%(p=0.095)$ or $5 \%(p=0.819)$ diatom filler groups, however, for the scaffolds the onset temperature was found to be significantly higher $(p \leq 0.05)$ than PDLGA. In pure-PDLGA printing the scaffolds resulted in further thermal degradation, which was found to be a significant reduction $(p=0.096)$ in temperature.

747 However, in both diatom groups no further reduction in thermal degradation was observed

748 after printing the scaffolds. This would suggest that the diatoms are somehow inhibiting thermal degradation. A similar phenomenon has been reported for inhibition of thermal degradation other polymers, such as PMMA by silica, where the surface area is high ${ }^{57}$. This is likely to be due to an interaction of the hydroxyl groups of the silica diatom surface with the carbonyl groups of the PLGA polyester. This causes PLGA molecules to absorb on the surface of the diatoms locally, thus reducing their molecular mobility, thereby rendering the molecules more stable. This effect is likely to be more pronounced the more surface area that is available for absorption. This unexpected advantageous property could be of significant benefit in 3D printing to minimise polymer degradation during processing while adding potential osteogenic benefit to the PDLGA. This phenomenon was not observed in Bioglass. There was a significant reduction $(P=0.0001)$ of $306.20( \pm 5.50)$ and $304.69( \pm$ 2.86) ${ }^{\circ} \mathrm{C}$ in the onset temperature for $5 \mathrm{wt}$. \% Bioglass-PDLGA for the filaments and scaffolds respectively. These results indicate that the addition of Bioglass significantly increases 
studies $^{4,5,49}$. Other studies investigating the addition of Bioglass into 3D composite scaffolds

763

764

765

766

767

768

769

770

771

772

773

774

775

776

777

778

779

780

781

782

783

784

using 3D printing, did not investigate the effect of Bioglass on the thermal stability of the polymers ${ }^{2,3}$. The effect of Bioglass on the onset temperature was studied further in the Bioglass filaments. In addition, the diatom biosilica filaments required a much higher temperature $\left(220\right.$ to $\left.225^{\circ} \mathrm{C}\right)$ to print compared to the Bioglass filaments $\left(165^{\circ} \mathrm{C}\right)$, however, the higher temperature did not cause any additional polymer degradation (Fig 8a). A study of the ceramic content with respect to onset temperature was performed on the filament in different sections. The results (Fig $8 b$ ) found that as the percentage of Bioglass increased, the onset temperature decreased, confirming that Bioglass reduced the thermal stability of the PDLGA with respect to the weight percentage added.

\section{Conclusion}

The study has demonstrated that both Bioglass and natural biosilica isolated from freshwater diatoms can be successfully 3D printed into a composite scaffold. The results found that natural diatom Biosilica had less impact on the PDLGA composites as indicated by thermo-mechanical properties, in comparison to those obtained from the Bioglass PDLGA composites. The addition of higher concentrations of diatoms was found to have significant impact on the toughness of the filaments. One of the most promising results was the ability of diatom Biosilica to inhibit thermal degradation of PDLGA. This holds significant promise for bone scaffolds as thermal degradation of polymers during FDM can compromise the mechanical integrity of the scaffold. Further analysis of the osteogenic potential of these diatom-PDLGA in both in vitro and in vivo systems is required to further assess their potential as a bone scaffold. 


\section{Acknowledgments:}

Funding by Department of Communications, Marine and Natural Resources, Ireland (Beaufort Marine Biodiscovery Programme). The authors would like to acknowledge Mark Billham and for his help with twin extrusion and Paula Douglas for running rheology samples from the School of Mechanical and Aerospace Engineering and also Angela Brownlie in ASEP (School of Chemistry and Chemical Engineering) running the TGA samples. The authors would like to thank Stephen Hull for editorial proofreading of this manuscript.

\section{References:}

1. Jones, J. R. Review of bioactive glass: From Hench to hybrids. Acta Biomaterialia (2012). doi:10.1016/j.actbio.2012.08.023

2. Alksne, M. et al. In vitro comparison of 3D printed polylactic acid/hydroxyapatite and polylactic acid/bioglass composite scaffolds: Insights into materials for bone regeneration. J. Mech. Behav. Biomed. Mater. (2020). doi:10.1016/j.jmbbm.2020.103641

3. Kleinfehn, A. P. et al. Modulating Bioglass Concentration in 3D Printed Poly(propylene fumarate) Scaffolds for Post-Printing Functionalization with Bioactive Functional Groups. Biomacromolecules (2019). doi:10.1021/acs.biomac.9b00941

4. Esslinger, S. \& Gadow, R. Additive manufacturing of bioceramic scaffolds by combination of FDM and slip casting. J. Eur. Ceram. Soc. (2019). doi:10.1016/j.jeurceramsoc.2019.10.029

5. Simpson, R. L. et al. A comparative study of the effects of different bioactive fillers in PLGA matrix composites and their suitability as bone substitute materials: A thermomechanical and in vitro investigation. J. Mech. Behav. Biomed. Mater. (2015). doi:10.1016/j.jmbbm.2015.06.008

6. Walsh, P. J., Clarke, S. A., Julius, M. \& Messersmith, P. B. Exploratory Testing of Diatom Silica to Map the Role of Material Attributes on Cell Fate. Sci. Rep. 7, (2017).

7. Amoda, A., Borkiewicz, L., Rivero-Müller, A. \& Alam, P. Sintered nanoporous biosilica diatom frustules as high efficiency cell-growth and bone-mineralisation platforms. Mater. Today Commun. (2020). doi:10.1016/j.mtcomm.2020.100923

8. Le, T. D. H., Liaudanskaya, V., Bonani, W., Migliaresi, C. \& Motta, A. Diatom Particles: A Promising Osteoinductive Agent of Silk Fibroin-Based Scaffold for Bone Regeneration. in IFMBE Proceedings (2020). doi:10.1007/978-981-13-5859-3_24

9. Le, T. D. H. et al. Processing and characterization of diatom nanoparticles and microparticles as potential source of silicon for bone tissue engineering. Mater. Sci. Eng. C (2016). doi:10.1016/j.msec.2015.10.040

10. Gordon, R., Losic, D., Tiffany, M. A., Nagy, S. S. \& Sterrenburg, F. A. S. The Glass Menagerie: diatoms for novel applications in nanotechnology. Trends in Biotechnology 27, 116-127 (2009).

11. Wu, D., Spanou, A., Diez-Escudero, A. \& Persson, C. 3D-printed PLA/HA composite structures as synthetic trabecular bone: A feasibility study using fused deposition modeling. J. Mech. Behav. Biomed. Mater. (2020). doi:10.1016/j.jmbbm.2019.103608

12. Cox, S. C., Thornby, J. A., Gibbons, G. J., Williams, M. A. \& Mallick, K. K. 3D printing of porous hydroxyapatite scaffolds intended for use in bone tissue engineering applications. Mater. Sci. Eng. C (2015). doi:10.1016/j.msec.2014.11.024

13. Jeon, H. J. et al. Fabrication and characterization of 3D-printed biocomposite scaffolds based on PCL and silanated silica particles for bone tissue regeneration. Chem. Eng. J. 
833

834

835

836

837

838

839

840

841

842

843

844

845

846

847

848

849

850

851

852

853

854

855

856

857

858

859

860

861

862

863

864

865

866

867

868

869

870

871

872

873

874

875

876

877

878

879

(2019). doi:10.1016/j.cej.2018.11.176

14. Pierantozzi, D. et al. 3D printed Sr-containing composite scaffolds: Effect of structural design and material formulation towards new strategies for bone tissue engineering. Compos. Sci. Technol. (2020). doi:10.1016/j.compscitech.2020.108069

15. Mobaraki, M., Ghaffari, M., Yazdanpanah, A., Luo, Y. \& Mills, D. K. Bioinks and bioprinting: A focused review. Bioprinting (2020). doi:10.1016/j.bprint.2020.e00080

16. Kim, J. et al. Rapid-prototyped PLGA/ $\beta$-TCP/hydroxyapatite nanocomposite scaffolds in a rabbit femoral defect model. Biofabrication (2012). doi:10.1088/1758$5082 / 4 / 2 / 025003$

17. Yen, H. J., Tseng, C. S., Hsu, S. H. \& Tsai, C. L. Evaluation of chondrocyte growth in the highly porous scaffolds made by fused deposition manufacturing (FDM) filled with type II collagen. Biomed. Microdevices (2009). doi:10.1007/s10544-008-9271-7

18. Little, H., Clarke, S. A., Cunningham, E. \& Buchanan, F. Process-induced degradation of bioresorbable PDLGA in bone tissue scaffold production. J. Mater. Sci. Mater. Med. (2018). doi:10.1007/s10856-017-6019-z

19. Jain, S., Fuoco, T., Yassin, M. A., Mustafa, K. \& Finne-Wistrand, A. Printability and Critical Insight into Polymer Properties during Direct-Extrusion Based 3D Printing of Medical Grade Polylactide and Copolyesters. Biomacromolecules (2020). doi:10.1021/acs.biomac.9b01112

20. Díaz-García et al. Novel procedure for laboratory scale production of composite functional filaments for additive manufacturing. Mater. Today Commun. (2020). doi:10.1016/j.mtcomm.2020.101049

21. Maniruzzaman, M. Pharmaceutical applications of hot-melt extrusion: Continuous manufacturing, twin-screw granulations, and 3D printing. Pharmaceutics (2019). doi:10.3390/pharmaceutics11050218

22. Daminabo, S. C., Goel, S., Grammatikos, S. A., Nezhad, H. Y. \& Thakur, V. K. Fused deposition modeling-based additive manufacturing (3D printing): techniques for polymer material systems. Mater. Today Chem. 16, 100248 (2020).

23. Melocchi, A. et al. Hot-melt extruded filaments based on pharmaceutical grade polymers for 3D printing by fused deposition modeling. Int. J. Pharm. (2016). doi:10.1016/j.ijpharm.2016.05.036

24. Hsu, S. H., Yen, H. J., Tseng, C. S., Cheng, C. S. \& Tsai, C. L. Evaluation of the growth of chondrocytes and osteoblasts seeded into precision scaffolds fabricated by fused deposition manufacturing. J. Biomed. Mater. Res. - Part B Appl. Biomater. (2007). doi:10.1002/jbm.b.30626

25. Singh, R. \& Ranjan, N. Experimental investigations for preparation of biocompatible feedstock filament of fused deposition modeling (FDM) using twin screw extrusion process. J. Thermoplast. Compos. Mater. (2018). doi:10.1177/0892705717738297

26. Julius, M. L. \& Theriot, E. C. The diatoms: a primer. diatoms Appl. ... (2010). doi:http://dx.doi.org/10.1017/CBO9780511763175.003

27. Dashnyam, K. et al. A mini review focused on the proangiogenic role of silicate ions released from silicon-containing biomaterials. Journal of Tissue Engineering (2017). doi:10.1177/2041731417707339

28. Nobile, S. \& Nobile, L. Recent research progress on scaffolds for bone repair and regeneration. in IFMBE Proceedings 68, (2019).

29. Polo-Corrales, L., Latorre-Esteves, M. \& Ramirez-Vick, J. E. Scaffold design for bone regeneration. Journal of Nanoscience and Nanotechnology (2014). 
880

881

882

883

884

885

886

887

888

889

890

891

892

893

894

895

896

897

898

899

900

901

902

903

904

905

906

907

908

909

910

911

912

913

914

915

916

917

918

919

920

921

922

923

924

925

926

doi:10.1166/jnn.2014.9127

30. Håkansson, H. \& Chepurnov, V. A study of variation in valve morphology of the diatom Cyclotella meneghiniana in monoclonal cultures: Effect of auxospore formation and different salinity conditions. Diatom Res. 14, 251-272 (1999).

31. Guo, T. et al. 3D printing PLGA: A quantitative examination of the effects of polymer composition and printing parameters on print resolution. Biofabrication (2017). doi:10.1088/1758-5090/aa6370

32. Kankala, R. K., Xu, X. M., Liu, C. G., Chen, A. Z. \& Wang, S. Bin. 3D-printing of microfibrous porous scaffolds based on hybrid approaches for bone tissue engineering. Polymers (Basel). (2018). doi:10.3390/polym10070807

33. Price, D. M., Hourston, D. J. \& Dumont, F. Thermogravimetry of Polymers. in Encyclopedia of Analytical Chemistry (2006). doi:10.1002/9780470027318.a2037

34. Berg, R. F. Fluids near a critical point obey a generalized Cox-Merz rule. J. Rheol. (N. Y. N. Y). (2004). doi:10.1122/1.1807843

35. Ahlinder, A., Fuoco, T. \& Finne-Wistrand, A. Medical grade polylactide, copolyesters and polydioxanone: Rheological properties and melt stability. Polym. Test. (2018). doi:10.1016/j.polymertesting.2018.10.007

36. Sprynskyy, M. et al. Naturally organic functionalized 3D biosilica from diatom microalgae. Mater. Des. (2017). doi:10.1016/j.matdes.2017.06.044

37. Arasuna, A. \& Okuno, M. Structural change of the frustule of diatom by thermal treatment. Geoscience Letters (2018). doi:10.1186/s40562-018-0101-3

38. Martin-Jézéquel, V., Hildebrand, M. \& Brzezinski, M. A. Silicon metabolism in diatoms: Implications for growth. Journal of Phycology (2000). doi:10.1046/j.15298817.2000.00019.x

39. Bienfang, P., Szyper, J. \& Laws, E. Sinking rate and pigment responses to lightlimitation of a marine diatom - implications to dynamics of chlorophyll maximum layers. Oceanol. Acta (1983).

40. Claquin, P., Martin-Jézéquel, V., Kromkamp, J. C., Veldhuis, M. J. W. \& Kraay, G. W. Uncoupling of silicon compared with carbon and nitrogen metabolisms and the role of the cell cycle in continuous cultures of Thalassiosira pseudonana (Bacillariophyceae) under light, nitrogen, and phosphorus control. J. Phycol. (2002). doi:10.1046/j.1529-8817.2002.t01-1-01220.x

41. Vrieling, E. G. et al. Salinity-dependent diatom biosilicification implies an important role of external ionic strength. Proc. Natl. Acad. Sci. U. S. A. (2007). doi:10.1073/pnas.0608980104

42. Shatwell, T., Köhler, J. \& Nicklisch, A. Temperature and photoperiod interactions with silicon-limited growth and competition of two diatoms. J. Plankton Res. (2013). doi:10.1093/plankt/fbt058

43. Hopkinson, B. M., Dupont, C. L., Allen, A. E. \& Morela, F. M. M. Efficiency of the CO2concentrating mechanism of diatoms. Proc. Natl. Acad. Sci. U. S. A. (2011). doi:10.1073/pnas.1018062108

44. Sumper, M., Kro, N., Regensburg, D.- \& Kr?ger, N. Silica formation in diatoms: the function of long-chain polyamines and silaffins. J. Mater. Chem. 14, 2059 (2004).

45. Chatzistavrou, X. et al. Following bioactive glass behavior beyond melting temperature by thermal and optical methods. in Physica Status Solidi (A) Applied Research (2004). doi:10.1002/pssa.200306776

46. Rajzer, I. et al. Electrospun polycaprolactone membranes with Zn-doped bioglass for 
933

934

935

936

937

938

939

940

941

942

943

944

945

946

947

948

949

950

951

952

953

954

955

956

957

958

959

960

961

962

963 nasal tissues treatment. J. Mater. Sci. Mater. Med. (2019). doi:10.1007/s10856-0196280-4

47. Fu, S. Y., Feng, X. Q., Lauke, B. \& Mai, Y. W. Effects of particle size, particle/matrix interface adhesion and particle loading on mechanical properties of particulatepolymer composites. Compos. Part B Eng. (2008). doi:10.1016/j.compositesb.2008.01.002

48. Zhou, S. et al. Hydrogen bonding interaction of poly(D,L-lactide)/hydroxyapatite nanocomposites. Chem. Mater. (2007). doi:10.1021/cm0619398

49. Blaker, J. J., Nazhat, S. N., Maquet, V. \& Boccaccini, A. R. Long-term in vitro degradation of PDLLA/Bioglass ${ }^{\circledR}$ bone scaffolds in acellular simulated body fluid. Acta Biomater. (2011). doi:10.1016/j.actbio.2010.09.013

50. Feih, S., Wei, J., Kingshott, P. \& Sørensen, B. F. The influence of fibre sizing on the strength and fracture toughness of glass fibre composites. in Composites Part A: Applied Science and Manufacturing (2005). doi:10.1016/j.compositesa.2004.06.019

51. Wang, G., Qu, X. \& Yu, Z. Changes in the mechanical properties and composition of bone during microdamage repair. PLoS One (2014). doi:10.1371/journal.pone.0108324

52. Xu, W., Wu, F., Jiao, Y. \& Liu, M. A general micromechanical framework of effective moduli for the design of nonspherical nano- and micro-particle reinforced composites with interface properties. Mater. Des. (2017). doi:10.1016/j.matdes.2017.04.075

53. Hamm, C. E. et al. Architecture and material properties of diatom shells provide effective mechanical protection. Nature 421, 841-843 (2003).

54. Park, J. Y. \& Zureick, A. H. Effect of filler and void content on mechanical properties of pultruded composite materials under shear loading. Polym. Compos. (2005). doi:10.1002/pc.20079

55. Mager, M. D., LaPointe, V. \& Stevens, M. M. Exploring and exploiting chemistry at the cell surface. Nat. Chem. 3, 582-589 (2011).

56. Shojaeiarani, J., Bajwa, D. S., Rehovsky, C., Bajwa, S. G. \& Vahidi, G. Deterioration in the physico-mechanical and thermal properties of biopolymers due to reprocessing. Polymers (Basel). (2019). doi:10.3390/polym11010058

57. Zou, D. Q. \& Yoshida, H. Size effect of silica nanoparticles on thermal decomposition of PMMA. in Journal of Thermal Analysis and Calorimetry (2010). doi:10.1007/s10973-009-0531-4 


\section{Declaration of interests}

$\bigotimes$ The authors declare that they have no known competing financial interests or personal relationships that could have appeared to influence the work reported in this paper.

$\square$ The authors declare the following financial interests/personal relationships which may be considered as potential competing interests: 